NBER WORKING PAPER SERIES

\title{
INTERNATIONAL EQUITY AND DEBT FLOWS: COMPOSITION, CRISIS, AND CONTROLS
}

\author{
Chang Ma \\ Shang-Jin Wei \\ Working Paper 27129 \\ http://www.nber.org/papers/w27129 \\ NATIONAL BUREAU OF ECONOMIC RESEARCH \\ 1050 Massachusetts Avenue \\ Cambridge, MA 02138 \\ May 2020, Revised December 2020
}

We thank Javier Bianchi, Charles Engel, Pierre-Olivier Gourinchas, Masashige Hamano, Jean Imbs, Olivier Jeanne, Yang Jiao, Anton Korinek, Hong Liu, Yang Liu, Alessandro Rebucci, John Rogers, Damiano Sandri, Stephanie Schmitt-Grohe and conference and seminar participants at Boston University, Columbia University, Conference on China and World Economy, 1st International Macro/Finance and Sovereign Debt Workshop in East Asia, Fudan University, International Macro Workshop at SUIBE, Thirteenth Annual Risk Management Conference in Singapore, Tsinghua Workshop in International Finance 2019, and Xiamen University for their helpful comments. We acknowledge excellent research assistance provided by Yuting Chen and Wei Li. Chang Ma gratefully acknowledges financial support from National Natural Science Foundation of China (Grant No. 72003043) and the Shanghai Pujiang Program. All errors are our own. The views expressed herein are those of the authors and do not necessarily reflect the views of the National Bureau of Economic Research.

NBER working papers are circulated for discussion and comment purposes. They have not been peerreviewed or been subject to the review by the NBER Board of Directors that accompanies official NBER publications.

(C) 2020 by Chang Ma and Shang-Jin Wei. All rights reserved. Short sections of text, not to exceed two paragraphs, may be quoted without explicit permission provided that full credit, including $\odot$ notice, is given to the source. 
International Equity and Debt Flows: Composition, Crisis, and Controls

Chang Ma and Shang-Jin Wei

NBER Working Paper No. 27129

May 2020, Revised December 2020

JEL No. F3

\section{ABSTRACT}

Standard models of capital flows to emerging market economies focus on debt flows and a pecuniary externality. However, by offering better risk sharing, international equity flows can render such externality unimportant, yet many economies fail to attract equity investment in a large quantity. We propose a theory of endogenous composition of capital flows that highlights two asymmetries. In our model, poor institutional quality leads to an inefficiently low share of equity financing as well as an inefficiently high volume of total inflows. Somewhat surprisingly, a social planner would often impose taxes on both equity and debt inflows. Our story differs in important ways from an alternative narrative focusing on collateral constraint.

\section{Chang Ma}

Fanhai International School of Finance

Fudan University

Shanghai, China 200433

machang.china@gmail.com

Shang-Jin Wei

Graduate School of Business

Columbia University

Uris Hall 619

3022 Broadway

New York, NY 10027-6902

and NBER

shangjin.wei@columbia.edu 


\section{Introduction}

Volatile international capital flows are recognized as a contributor to financial crises and consumption volatility in emerging market economies. The literature has highlighted two types of externalities in this context. First, when the economy faces an aggregate borrowing constraint, private agents do not take into account a pecuniary externality that their individual borrowing action creates for the value of the total collateral in the economy. This causes them to over-borrow relative to what a social planner would prefer. When a negative shock is realized, the economy can contract unnecessarily, in the sense that an ex ante tax on borrowing could correct the problem and raise the welfare (Lorenzoni (2008), Mendoza (2010), Bianchi (2011), Benigno, Chen, Otrok, Rebucci, and Young (2013), Jeanne and Korinek (2018) and Korinek (2018)). With the same pecuniary externality in the debt market, a sunspot equilibrium can also feature swings between under-borrowing and overborrowing that can also produce sudden stops in capital flows (Schmitt-Grohé and Uribe (forthcoming)). Second, in the presence of sticky wages or prices and a fixed exchange rate regime, private agents' borrowing may not take into account an externality on the demand side that can also trigger an inefficiently low level of output and employment. Again, a tax on private sector borrowing may raise welfare (Farhi and Werning (2014, 2016), Korinek and Simsek (2016) and Schmitt-Grohé and Uribe (2016)). In all such theories, the focus is on international debt flows.

International equity flows, however, are qualitatively different due to their intrinsically better risk-sharing property. In particular, if equity financing is available, and international investors are risk neutral (which is a common assumption in this literature), then the emerging market economies can in principle offload all of their risk to international investors. The pecuniary externality would not matter since the emerging market economy that is financed entirely by foreign equity investment would not run into the aggregate borrowing constraint. The demand externality would not matter either since the effect of a negative domestic shock would be fully borne by foreign equity investors. ${ }^{1}$ In both scenarios, the optimal tax on capital flows is zero.

Of course, a country's ability to obtain international equity financing varies greatly,

\footnotetext{
${ }^{1}$ As demonstrated in Appendix D, when the institutional quality is sufficiently good, the economy is financed by equity flows only and offloads all the risks to international investors. As a result, shocks to tradable output do not generate aggregate demand externality or inefficiency.
} 
and many emerging market economies can be observed to take on a large quantity of debt from the international capital market. The first objective of this paper is to understand the cross-country variations in the composition of capital flows. We will propose a theory in which a country's institutional quality will play a central role in the determination of the composition. We will show that the share of equity financing in a country's external liabilities tends to rise with the quality of the country's institutions. (Correspondingly, the probability of a debt crisis declines with the institutional quality.)

The second objective of the paper is to investigate the optimal structure of capital controls in such an economy. One result that may be counter-intuitive at the first sight is that the optimal regime typically features a positive tax on both equity and debt if the country's institutional quality is below some threshold. This is somewhat surprising because we have just said that international equity financing has a desirable risk-sharing property, and an economy that is financed entirely by equity investment achieves the first best. But it is consistent with the common pattern in the data that many countries with restrictions on cross-border debt flows also tend to have restrictions on cross-border equity flows. Our theory will clarify the logic behind this seeming paradox.

The attention to external capital structure is motivated in part by a recent literature suggesting that the composition of capital inflows matters for the experience of countries during global financial crises (see Forbes and Warnock (2012)). For example, countries with a relatively high share of debt (as opposed to FDI or equity investment) fare worse during financial crises (see Tong and Wei (2010)). In our model, the quality of domestic institutions determines the share of equity in the country's total external liability, which in turn determines the total volatility of capital flows. Countries with good institutional quality (e.g., typical developed countries) can issue more equity-like securities and are therefore less likely to run into sudden stop episodes. As a result, they have less need to use capital controls to manage their capital flows. On the other hand, countries with weaker public institutions (i.e., typical developing countries) need to rely more heavily on debt instruments for financing and are more exposed to the risk of sudden stops. As a result, capital controls are more necessary for them.

If some external capital structure is riskier than others, why do so many countries live with the unfavorable structure? One conjecture is that the quality of domestic institution is an important determinant of the external capital structure (see Wei (2000) and Wei and 
Figure 1 Equity Share ANd Institutional Quality: Bin Scatter Plot

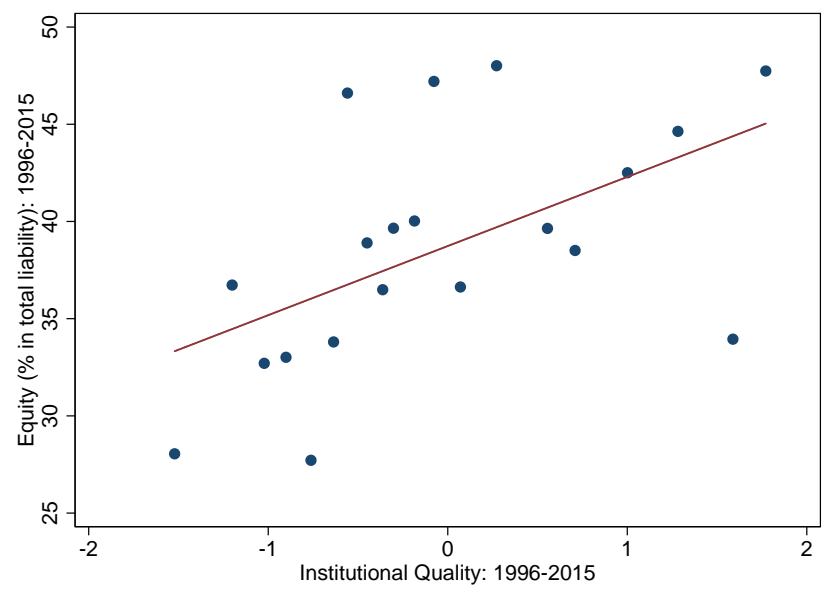

NOTE. This is a bin scatter plot of the average equity share (in \% of total external liability) against the average institutional quality during 1996-2015 across countries. The slope of the fitted line is 3.56 with a t-statistic at 3.71. See Appendix A for the country coverage, Appendix B for data sources and variable construction, and Section 2 for additional regression results.

Zhou (2018)). Because equity investment does not have a pre-specified fixed payoff, the payoff to equity investors is more dependent on legal and other institutions than debt contract. In the language of Holmstrom (2015), debt is a lot less "information intensive," and is much less demanding on the ability of international investors to collect, analyze, and understand information about the nature of the investment projects and the full payoff of the underlying projects. When a country has an inadequate legal protection of investor rights, foreign equity investors are more concerned than foreign debt investors. As a result, there will be relatively less demand for equity-like securities from that country. This intuition is reflected in a bin scatter plot in Figure 1, which shows a strongly positive relationship across countries between the quality of a country's public institutions and the share of equity in its total external liability during 1996-2015. In a similar vein, Modigliani and Perotti (2000) show that, in countries with weak investor protection, investment is more likely to be financed by bank loans than by the equity market.

As countries with poor domestic institutions are more likely to issue debt-like securities, they in turn are also more susceptible to sudden stop episodes. In other words, a country's experience with sudden stops is not random. Instead, it is related to the external 
capital structure and domestic institutional quality. ${ }^{2}$ The theory that we propose suggests that a country's external capital structure would naturally vary by the stage of economic development (as captured by the quality of public institution). As a country becomes more developed (or sees improvement in its institutions), a greater share of its external liabilities would feature risk sharing between the capital recipient country and the international investors. Moreover, the optimal level of capital controls also declines.

The parameter denoting the degree of collateral constraint is often thought of as representing the level of financial development in the existing literature. It is natural to ask whether cross-country variations in that parameter can generate the same patterns as our institutional quality story. The short answer is no. While either a relaxed borrowing constraint or improved institutions result in fewer crises, the two are different in important ways. First, while an improvement in institutions leads to a higher share of equity financing in a country's external liabilities, a relaxation of the collateral constraint leads to an opposite change (i.e., a lower equity share). Second, while a higher institutional quality reduces the required level of capital controls needed to remove economic inefficiency, a more relaxed collateral constraint leads to the opposite result. For example, Bianchi (2011), in the simulation part of his model (Panel $\mathrm{C}$ of Figure 6), reports that the optimal average tax on capital flows would increase as the collateral constraint on borrowing relaxes.

Comparing middle-income with poor countries, or comparing developed with developing countries, there are differences in both the quality of public institutions that limit expropriation risks and financial development that affects the extent of collateral constraint in borrowing from the international debt market. Our evidence will suggest that, to understand cross-country differences in the patterns of capital flows, differences in institutions are more important than differences in collateral constraint.

As a general implication, the optimal strategy for financial stability should depend on a country's institutional quality. A higher quality of domestic institutions leads to a safer external capital structure and therefore a higher level of financial stability. In this case, there is no need for restrictions on cross-border capital flows. On the other hand, a poor domestic institutional quality reduces the country's ability to issue equity-like securities

\footnotetext{
${ }^{2}$ Our theory also provides a partial explanation for a home bias in the equity market in emerging market economies (see Coeurdacier and Rey (2013) for a survey). As the poor institutional quality repels foreign investors from providing equity financing, the domestic agents have to hold more home equities in their portfolio than a full risk-sharing model without expropriation risk would have predicted.
} 
and this leads to more financial vulnerability. In this scenario, capital control policies are needed to correct this inefficiency. These results suggest that if there is a way to improve a country's domestic institutional quality, it is worth pursuing, because it allows the country to fully utilize the benefits from financial globalization (see Kose, Prasad, Rogoff, and Wei (2010)). If a country is unable to improve its institutional quality, capital controls can then be used to correct this inefficiency and externality. The need for capital controls declines as an economy matures in the form of improved institutions.

Throughout the paper, we assume that a country's institutional quality is a deep parameter. The justification is that relative to policies on interest rate, tax rate, and capital controls, a country's institutional quality is a much slower moving object and much harder to change. In future work, one may also consider endogenous determination of institutional quality, perhaps along the line of Jiao and Wei (2017).

We discuss a number of extensions in Section 5. First, while there is only one type of equity financing in the baseline model, we will consider foreign direct investment (with control rights) and passive equity investment jointly. One new insight is that the ratio of FDI to passive equity investment tends to decline as a country's institutional quality rises. Second, while the baseline model assumes that a typical emerging market economy can only borrow in a foreign currency (e.g., the US dollar), we will allow for endogenous local-currency borrowing as well. One new insight is that the local-currency debt emerges in equilibrium only when the capital recipient country has sufficiently good institutions. Third, while the baseline model only features short-term debt (as in the existing literature on the debt problems in emerging market economies), we will also consider debt of different maturities. A key insight is that a long-term debt provides better risk-sharing but a country's debt maturity structure depends on its institutional quality as well.

We make two main contributions to the literature. First, we provide a theory of external capital structure across countries (e.g., the relative importance of equity versus debt financing). Compared to the existing literature on capital flows to emerging market economies (Bianchi (2011) and Korinek (2018)) which features only debt flows, we augment the menu of capital flows by adding equity financing. ${ }^{3}$ The existing literature on over-borrowing can be regarded as a special case of our theory where equity financing is ruled out by assump-

\footnotetext{
${ }^{3}$ Arce, Bengui, and Bianchi (2019) study the patterns of private debt flows and foreign exchange reserve accumulation in a model similar to Bianchi (2011).
} 
tion and debt is the only available funding source. Alternatively, this case can emerge endogenously in our model when the domestic institutional quality is below some threshold value. In general, however, both equity and debt financing co-exist in equilibrium. Their relative importance across countries affects the relative financial stability.

Second, we enrich the discussion on the design of capital controls. In the existing literature, the source of market inefficiency is either a pecuniary externality (see Lorenzoni (2008), Jeanne and Korinek (2010), and Dávila and Korinek (2018)) or an aggregate demand externality (see Farhi and Werning (2016) and Korinek and Simsek (2016)), but these papers do not investigate how the source of inefficiency may vary as a function of country conditions. In our model, the quality of institutions plays the role of a deep parameter that determines the external capital structure and correspondingly the optimal capital controls. Because most of the literature has featured only debt, a capital control is simply a tax on debt flows. For example, using a small open economy dynamic stochastic general equilibrium (DSGE) framework, Bianchi (2011), Benigno et al. (2013), Jeanne and Korinek (2018), Bianchi and Mendoza (2018), and Ma (2020) have computed such a tax. In comparison, by allowing for multiple forms of capital flows simultaneously, we have to specify a structure of capital controls. ${ }^{4}$ As stated earlier, one somewhat surprising result is that the social planner would often impose taxes on both equity and debt flows even though the equity flows are supposed to have a better risk-sharing property. This is explained in our model by a spillover of externality from the debt market to equity financing. We will show that this prediction is borne out in the data as well: countries with controls on debt flows often also have controls on equity flows. To the best of our knowledge, this is the first model that rationalizes this pattern. In any case, the optimal capital controls should change as a function of the institutional quality. Our theory also explains why capital controls are more commonly observed for developing countries than for developed countries.

This paper is organized as follows: Section 2 presents three empirical patterns that motivate our research; Section 3 presents our benchmark model; Section 4 contrasts financial development with institutional improvement; Section 5 presents several extensions; and Section 6 concludes. Additional information is provided in online Appendices.

\footnotetext{
${ }^{4}$ Korinek (2018) provides a general framework to analyze the issuance of state-contingent security. He points out that equity has less externality than debt. However, the two cases are analyzed separately. In this paper, the composition of debt and equity is jointly determined in equilibrium.
} 


\section{Some Data Patterns}

In this section, we distill some data patterns on international capital flows that will motivate and guide our theory in the next section. We document three patterns in particular:

Fact 1. The share of equity financing in total external liability tends to rise with the strength of a country's institutional quality. This is consistent with Figure 1. This relationship still holds after we control from income, trade openness, and (domestic) financial development.

Fact 2. Financial crises are less frequent in countries with more equity financing in share of their total external liability.

Fact 3. Countries with a lower quality of institutions tend to have more restrictions on both cross-border equity flows and debt flows.

To establish these facts, we combine data sets from five sources for 159 economies during 1996-2015: the External Wealth of Nations (EWN) data set from Lane and MilesiFerretti (2007), the Worldwide Governance Indicators (WGI) from the World Bank Institute, and data on sudden stop episodes from Korinek and Mendoza (2014), banking crises from Laeven and Valencia (2013), and capital controls from Fernández, Klein, Rebucci, Schindler, and Uribe (2016). The details on the country lists and construction of variables are given in Appendices A and B, respectively.

Note that, in this section, equity financing refers to the sum of inward foreign direct investment and inward portfolio equity investment. The difference between equity and debt financing is what we wish to focus on in our baseline model in the next section. However, we will consider various differentiation within the broad equity category (FDI versus passive portfolio equity investment) and within the broad debt category (e.g., shortterm versus long-term debt) in Section 5.

In Table 1, we examine the relationship between the equity share in a country's external liability and its institutional quality in both panel regressions and a long-differencing setting. In Panel A, we present panel regressions with random effects in column (1) and country and year fixed effects in columns (2) and (3), respectively. On average, countries with better institutions do exhibit a higher share of equity financing. Using the point estimate in Column (2) as an illustration, an improvement in the institutional quality by one 
Table 1 EXTERnAl CAPITAL STRUCTURE AND Institutional QUALiTy

\begin{tabular}{|c|c|c|c|c|c|}
\hline & \multirow{2}{*}{\multicolumn{3}{|c|}{$\begin{array}{c}\text { Panel A: Panel Regression: 1996-2015 } \\
\text { Equity share (\% in total liability) }\end{array}$}} & \multirow{2}{*}{\multicolumn{2}{|c|}{$\begin{array}{c}\text { Panel B: Cross Section: } 1996-2015 \\
\Delta_{1997-2015} \text { Equity share (\% in total liability) }\end{array}$}} \\
\hline & & & & & \\
\hline & (1) & (2) & (3) & & (4) \\
\hline Quality $(t-1)$ & $\begin{array}{l}1.99 * \\
(1.10)\end{array}$ & $\begin{array}{c}6.90 * * \\
(3.38)\end{array}$ & $\begin{array}{c}9.21 * * * \\
(3.47)\end{array}$ & $\Delta_{1996-2014}$ Quality & $\begin{array}{l}10.16^{*} \\
(5.54)\end{array}$ \\
\hline Log GDP per capita $(t-1)$ & & & $\begin{array}{l}-6.67 \\
(4.26)\end{array}$ & $\Delta_{1996-2014}$ Log GDP per capita & $\begin{array}{l}-2.77 \\
(4.90)\end{array}$ \\
\hline Private Credit $(t-1)$ & & & $\begin{array}{l}-0.12 * * * \\
(0.05)\end{array}$ & $\Delta_{1996-2014}$ Private Credit & $\begin{array}{l}-0.07 \\
(0.06)\end{array}$ \\
\hline Trade $(t-1)$ & & & $\begin{array}{c}0.01 \\
(0.03)\end{array}$ & $\Delta_{1996-2014}$ Trade & $\begin{array}{c}0.06 \\
(0.05)\end{array}$ \\
\hline Observations & 2697 & 2697 & 2697 & Observations & 144 \\
\hline Random Effects & $\mathrm{Y}$ & $\mathrm{N}$ & $\mathrm{N}$ & & \\
\hline Year FE & $\mathrm{N}$ & Y & Y & & \\
\hline Country FE & $\mathrm{N}$ & $\mathrm{Y}$ & Y & & \\
\hline Cluster at Country-level & $\mathrm{N}$ & Y & Y & & \\
\hline$R^{2}$ & 0.0145 & 0.411 & 0.436 & $R^{2}$ & 0.015 \\
\hline
\end{tabular}

NOTE. Dependent variable in Panel A is the equity share (portfolio equity and FDI) in total liability while the independent variables are lagged by one year. Dependent in Panel B is the change of equity share (portfolio equity and FDI) in total liability between 1997 and 2015 while the independent variable is the change between 1996 and 2014. All standard errors in reported in parentheses. ${ }^{*} p<0.10,{ }^{* *} p<0.05,{ }^{* * *} p<0.01$.

standard deviation is associated with a higher share of equity by 6.3 percentage points, or around $31 \%$ of one standard deviation of the equity share in the sample. ${ }^{5}$ The coefficients on the control variables are also consistent with the existing literature (see Wei and Zhou (2018)). This positive relationship continues to be true when we include per capita GDP, domestic credit to private sector as a share of GDP (a common measure of domestic financial development), and trade/GDP ratio (a common measure of trade openness). In fact, the coefficient on institutional quality becomes larger by 33 percent.

In Panel B, we examine the same relationship in a long-difference. That is, the dependent variable is the change in a country's equity financing in total external liability from 1997 to 2015. The regressors are the changes in institutional quality, log GDP per capita, domestic financial development, and trade openness, respectively, from 1996 to 2014. The

\footnotetext{
${ }^{5}$ The unconditional share of equity is $38.6 \%$. One standard deviation increase in the institutional quality (by 0.92 ) is associated with an increase in the equity share by $6.90 * 0.92=6.3 \%$, or $31 \%=6.3 / 20.55$ of one standard deviation of the equity share across countries.
} 
Table 2 FinAnCial Crises ANd External Capital Structure

\begin{tabular}{|c|c|c|c|c|c|c|c|c|}
\hline & \multicolumn{4}{|c|}{ Sudden Stop Crises } & \multicolumn{4}{|c|}{ Systemic Banking Crises } \\
\hline & (1) & (2) & (3) & (4) & (5) & (6) & (7) & (8) \\
\hline Equity Share $(t-1)$ & $\begin{array}{l}-0.03 * * * \\
(0.01)\end{array}$ & $\begin{array}{l}-0.05 * * * \\
(0.02)\end{array}$ & $\begin{array}{l}-0.03 * * * \\
(0.01)\end{array}$ & $\begin{array}{l}-0.05 * * \\
(0.02)\end{array}$ & $\begin{array}{l}-0.04 * * * \\
(0.01)\end{array}$ & $\begin{array}{l}-0.06 * * * \\
(0.01)\end{array}$ & $\begin{array}{l}-0.04 * * * \\
(0.01)\end{array}$ & $\begin{array}{l}-0.04 * * * \\
(0.01)\end{array}$ \\
\hline Log GDP per capita $(t-1)$ & & & $\begin{array}{l}-0.22 \\
(0.26)\end{array}$ & $\begin{array}{l}0.87 \\
(1.59)\end{array}$ & & & $\begin{array}{l}-0.28 \\
(0.46)\end{array}$ & $\begin{array}{l}-2.18^{*} \\
(1.22)\end{array}$ \\
\hline Private Credit $(t-1)$ & & & $\begin{array}{l}0.00 \\
(0.00)\end{array}$ & $\begin{array}{l}0.00 \\
(0.01)\end{array}$ & & & $\begin{array}{l}0.04 * * * \\
(0.01)\end{array}$ & $\begin{array}{l}0.06^{* * *} * \\
(0.01)\end{array}$ \\
\hline Trade $(t-1)$ & & & $\begin{array}{l}0.00 \\
(0.00)\end{array}$ & $\begin{array}{l}-0.00 \\
(0.01)\end{array}$ & & & $\begin{array}{l}0.01 * \\
(0.00)\end{array}$ & $\begin{array}{l}0.02 * * \\
(0.01)\end{array}$ \\
\hline Random-effects & Yes & No & Yes & No & Yes & No & Yes & No \\
\hline Country FE & No & Yes & No & Yes & No & Yes & No & Yes \\
\hline Time FE & Yes & Yes & Yes & Yes & Yes & Yes & Yes & Yes \\
\hline Observations & 928 & 736 & 892 & 708 & 2016 & 1083 & 1910 & 999 \\
\hline
\end{tabular}

Note. All columns are based on panel Logit model. Dependent variable is the dummy for crises. Column (1)-(4) use crises identified by Korinek and Mendoza (2014) while column (5)-(8) use crises identified by Laeven and Valencia (2013). Standard errors are in parentheses. ${ }^{*} p<0.10,{ }^{* *} p<0.05,{ }^{* * *} p<0.01$.

long-differencing not only removes all time-invariant variables that may affect the equity share but also allows the cumulative effect on equity share to reveal itself. With this specification, we continue to find a positive and statistically significant relationship between a country's institutional quality and the equity financing in percent of its external liability. The size of the point estimate on institutional quality becomes larger still than the corresponding coefficient in the panel regressions.

In Table 2, we examine the relationship between financial instability and the share of equity financing in a country's external liabilities. We use two indicators of financial crises: one for the presence of a banking crisis in a country-year as identified by Laeven and Valencia (2013) and the other for the presence of a sudden stop episode in a country-year as identified by Korinek and Mendoza (2014). The banking crisis indicator is constructed to capture financial distress in the banking system while the sudden stop indicator is constructed to capture sharp reversals in current account balances.

We use a panel Logit model to connect the probability of a crisis to the structure of external liability, controlling for economic development, private credit as a share of GDP, and time fixed effects. We also allow for either country fixed effects (in columns (2), (4), 
(6), and (8)) or random effects (in columns (1), (3), (5), and (7)). Our results suggest that a higher share of equity is associated with a reduced probability of both a banking crisis and a sharp current account reversal and the effects are statistically significant. This result is consistent with the existing literature such as Tong and Wei (2010). Using Column (4) as an example, an increase in the equity share in total liability by 20 percentage points, or roughly 1 standard deviation in the sample, is associated with a reduction in the incidence of sudden stop crises by 1 percentage point. The negative association between the equity share and the probability of a crisis holds for a variety of model specifications. This result is also consistent with the literature that emphasizes a higher leverage as a predictor of future crises (see Frankel and Rose (1996) and Adrian and Shin (2014) for example).

In Table 3, we report the relationship between capital controls and institutional quality across countries. We focus on the restrictions imposed by country authorities on foreign purchases of domestic debt and equities, respectively (see Fernández et al. (2016)). Specifically, the restrictions on equity (EQ), collective investment securities (CI), derivatives (DE) and direct investment (DI) are grouped into controls on equity financing, while the restrictions on bonds with an original maturity of more than one year (BO), money market instruments (MM), commercial credits (CC) and financial credits (FC) are grouped into capital controls on debt financing. As the underlying measures are dummy indicators for the absence or presence of restrictions, they do not measure the intensity of controls.

We use a probit and logit model to conduct our analysis with country controls and time fixed effects. We allow for either random or country fixed effects. As a robustness check, we also present results with linear probability (OLS) regressions. In addition, we estimate ordered Probit and Logit models. Across all these specifications, we see a clear negative relationship between a country's quality of institutions and the presence of capital controls. That is, a country is more likely to impose capital account restrictions when it has a poorer institutional quality. This continues to be true after we control for economic development.

It is noteworthy that the relationship holds for restrictions on both equity flows and debt flows. That is, in countries with low-quality institutions, capital account restrictions tend to be placed on both equity and debt flows. As we will note later, this might appear surprising at the first look given the better risk sharing property of equity flows. We will provide a way to understand this data pattern in our model.

In sum, a country's institutional quality appears to be a robust predictor for its external 
Table 3 CAPITAL CONTROLS AND INSTITUTIONAL QUALITY

\begin{tabular}{|c|c|c|c|c|c|c|c|c|c|c|}
\hline \multicolumn{11}{|c|}{ Panel A: Fixed Effects Model } \\
\hline & \multicolumn{2}{|c|}{ OLS } & \multicolumn{2}{|c|}{ Probit Model } & \multicolumn{2}{|c|}{ Logit Model } & \multicolumn{2}{|c|}{ Ordered Probit Model } & \multicolumn{2}{|c|}{ Ordered Logit Model } \\
\hline & $\begin{array}{c}\text { Equity } \\
\text { (1) }\end{array}$ & $\begin{array}{l}\text { Debt } \\
(2)\end{array}$ & $\begin{array}{l}\text { Equity } \\
\text { (3) }\end{array}$ & $\begin{array}{c}\text { Debt } \\
(4)\end{array}$ & $\begin{array}{l}\text { Equity } \\
\text { (5) }\end{array}$ & $\begin{array}{c}\text { Debt } \\
(6)\end{array}$ & $\begin{array}{l}\text { Equity } \\
\text { (7) }\end{array}$ & $\begin{array}{c}\text { Debt } \\
(8)\end{array}$ & $\begin{array}{l}\text { Equity } \\
\text { (9) }\end{array}$ & $\begin{array}{l}\text { Debt } \\
(10)\end{array}$ \\
\hline Quality & $\begin{array}{c}-0.25^{*} \\
(0.14)\end{array}$ & $\begin{array}{l}-0.22 \\
(0.16)\end{array}$ & $\begin{array}{c}-1.18 * * \\
(0.49)\end{array}$ & $\begin{array}{c}-1.83 * * * \\
(0.52)\end{array}$ & $\begin{array}{c}-1.99 * * \\
(0.86)\end{array}$ & $\begin{array}{c}-3.05 * * * \\
(0.90)\end{array}$ & $\begin{array}{c}-1.29 * * \\
(0.50)\end{array}$ & $\begin{array}{c}-1.49 * * \\
(0.73)\end{array}$ & $\begin{array}{c}-2.46^{* * *} * \\
(0.91)\end{array}$ & $\begin{array}{l}-2.45^{*} \\
(1.43)\end{array}$ \\
\hline Log GDP per capita & $\begin{array}{l}-0.22^{*} \\
(0.13)\end{array}$ & $\begin{array}{l}-0.03 \\
(0.14)\end{array}$ & $\begin{array}{c}-2.18 * * * \\
(0.73)\end{array}$ & $\begin{array}{l}-0.26 \\
(0.73)\end{array}$ & $\begin{array}{c}-4.17 * * * \\
(1.34)\end{array}$ & $\begin{array}{c}-0.65 \\
(1.28)\end{array}$ & $\begin{array}{l}-1.31^{*} \\
(0.74)\end{array}$ & $\begin{array}{l}-0.10 \\
(0.80)\end{array}$ & $\begin{array}{l}-2.06 \\
(1.43)\end{array}$ & $\begin{array}{l}-0.43 \\
(1.49)\end{array}$ \\
\hline Private Credit & $\begin{array}{l}-0.00 \\
(0.00)\end{array}$ & $\begin{array}{c}0.00 \\
(0.00)\end{array}$ & $\begin{array}{c}-0.01 * * \\
(0.00)\end{array}$ & $\begin{array}{l}0.01 * \\
(0.00)\end{array}$ & $\begin{array}{c}-0.02 * * \\
(0.01)\end{array}$ & $\begin{array}{c}0.01 * * \\
(0.01)\end{array}$ & $\begin{array}{c}-0.01 * * \\
(0.00)\end{array}$ & $\begin{array}{l}-0.00 \\
(0.00)\end{array}$ & $\begin{array}{c}-0.01 * * \\
(0.01)\end{array}$ & $\begin{array}{l}-0.01 \\
(0.01)\end{array}$ \\
\hline Trade & $\begin{array}{c}0.00 \\
(0.00)\end{array}$ & $\begin{array}{c}0.00 \\
(0.00)\end{array}$ & $\begin{array}{l}0.01 * \\
(0.00)\end{array}$ & $\begin{array}{c}0.01 * * \\
(0.01)\end{array}$ & $\begin{array}{l}0.01 * \\
(0.01)\end{array}$ & $\begin{array}{c}0.02 * * \\
(0.01)\end{array}$ & $\begin{array}{c}0.00 \\
(0.00)\end{array}$ & $\begin{array}{c}0.01 \\
(0.01)\end{array}$ & $\begin{array}{c}0.01 \\
(0.01)\end{array}$ & $\begin{array}{c}0.01 \\
(0.01)\end{array}$ \\
\hline Year FE & Yes & Yes & Yes & Yes & Yes & Yes & Yes & Yes & Yes & Yes \\
\hline Observations & 1680 & 1653 & 705 & 646 & 705 & 646 & 1680 & 1653 & 1680 & 1653 \\
\hline \multicolumn{11}{|c|}{ Panel B: Random Effects Model } \\
\hline & \multicolumn{2}{|c|}{ OLS } & \multicolumn{2}{|c|}{ Probit Model } & \multicolumn{2}{|c|}{ Logit Model } & \multicolumn{2}{|c|}{ Ordered Probit Model } & \multicolumn{2}{|c|}{ Ordered Logit Mode } \\
\hline & $\begin{array}{c}\text { (11) } \\
\text { Equity }\end{array}$ & $\begin{array}{l}(12) \\
\text { Debt }\end{array}$ & $\begin{array}{c}\text { (13) } \\
\text { Equity }\end{array}$ & $\begin{array}{l}\text { (14) } \\
\text { Debt }\end{array}$ & $\begin{array}{l}\text { (15) } \\
\text { Equity }\end{array}$ & $\begin{array}{l}(16) \\
\text { Debt }\end{array}$ & $\begin{array}{l}\text { (17) } \\
\text { Equity }\end{array}$ & $\begin{array}{l}(18) \\
\text { Debt }\end{array}$ & $\begin{array}{l}\text { (19) } \\
\text { Equity }\end{array}$ & $\begin{array}{l}\text { (20) } \\
\text { Debt }\end{array}$ \\
\hline Quality & $\begin{array}{c}-0.25^{* *} \\
(0.12)\end{array}$ & $\begin{array}{l}-0.19^{*} \\
(0.11)\end{array}$ & $\begin{array}{c}-1.63 * * \\
(0.82)\end{array}$ & $\begin{array}{l}-1.71 * \\
(0.99)\end{array}$ & $\begin{array}{l}-2.88^{*} \\
(1.68)\end{array}$ & $\begin{array}{l}-2.94^{*} \\
(1.73)\end{array}$ & $\begin{array}{c}-1.31 * * * \\
(0.43)\end{array}$ & $\begin{array}{c}-1.28 * * \\
(0.53)\end{array}$ & $\begin{array}{c}-2.46^{* * *} * \\
(0.77)\end{array}$ & $\begin{array}{c}-2.16^{* *} \\
(1.03)\end{array}$ \\
\hline Log GDP per capita & $\begin{array}{l}-0.10 \\
(0.09)\end{array}$ & $\begin{array}{l}-0.04 \\
(0.08)\end{array}$ & $\begin{array}{l}-0.94 \\
(0.97)\end{array}$ & $\begin{array}{l}-0.38 \\
(0.77)\end{array}$ & $\begin{array}{l}-2.15 \\
(2.50)\end{array}$ & $\begin{array}{l}-0.76 \\
(1.28)\end{array}$ & $\begin{array}{l}-0.77 \\
(0.57)\end{array}$ & $\begin{array}{l}-0.31 \\
(0.52)\end{array}$ & $\begin{array}{l}-1.22 \\
(1.06)\end{array}$ & $\begin{array}{l}-0.70 \\
(0.96)\end{array}$ \\
\hline Private Credit & $\begin{array}{l}-0.00 \\
(0.00)\end{array}$ & $\begin{array}{c}0.00 \\
(0.00)\end{array}$ & $\begin{array}{l}-0.01 \\
(0.01)\end{array}$ & $\begin{array}{c}0.01 \\
(0.01)\end{array}$ & $\begin{array}{l}-0.01 \\
(0.01)\end{array}$ & $\begin{array}{c}0.01 \\
(0.01)\end{array}$ & $\begin{array}{l}-0.01 * \\
(0.00)\end{array}$ & $\begin{array}{l}-0.00 \\
(0.00)\end{array}$ & $\begin{array}{l}-0.01 * \\
(0.01)\end{array}$ & $\begin{array}{l}-0.01 \\
(0.01)\end{array}$ \\
\hline Trade & $\begin{array}{c}0.00 \\
(0.00)\end{array}$ & $\begin{array}{c}0.00 \\
(0.00)\end{array}$ & $\begin{array}{c}0.01 \\
(0.01)\end{array}$ & $\begin{array}{c}0.01 \\
(0.01)\end{array}$ & $\begin{array}{c}0.01 \\
(0.01)\end{array}$ & $\begin{array}{c}0.01 \\
(0.01)\end{array}$ & $\begin{array}{c}0.00 \\
(0.00)\end{array}$ & $\begin{array}{c}0.00 \\
(0.00)\end{array}$ & $\begin{array}{c}0.00 \\
(0.01)\end{array}$ & $\begin{array}{c}0.01 \\
(0.01)\end{array}$ \\
\hline $\begin{array}{l}\text { Year FE } \\
\text { Observations }\end{array}$ & $\begin{array}{c}\text { Yes } \\
1680\end{array}$ & $\begin{array}{c}\text { Yes } \\
1653\end{array}$ & $\begin{array}{c}\text { Yes } \\
1680\end{array}$ & $\begin{array}{c}\text { Yes } \\
1653\end{array}$ & $\begin{array}{c}\text { Yes } \\
1680\end{array}$ & $\begin{array}{c}\text { Yes } \\
1653\end{array}$ & $\begin{array}{c}\text { Yes } \\
1680\end{array}$ & $\begin{array}{c}\text { Yes } \\
1653\end{array}$ & $\begin{array}{c}\text { Yes } \\
1680\end{array}$ & $\begin{array}{c}\text { Yes } \\
1653\end{array}$ \\
\hline
\end{tabular}

NOTE. Panels A and B present fixed effects and random effects models, respectively. The dependent variable for Columns (1), (3), (5), (11), (13) and (15) is a dummy for the presence of restrictions on equity inflows, and takes the value of one if a restriction is placed on any of the following: "shares or other securities of a participating nature", "collective investment securities", "derivatives and other instruments" or "direct investment". The dependent variable for Columns (2), (4), (6), (12), (14) and (16) is a dummy for restrictions on debt inflows and takes the value of one if a restriction is placed on any of the following: "bonds or other debt securities", "money market instruments", "commercial credits", or "financial credits", based on on the information in Fernández et al. (2016). The dependent variable in both the ordered Probit and Logit models (Columns (7)-(10) and (17)-(20)) is a count of the number of relevant asset categories that face restrictions. The ordered probit (logit) in Panel A is estimated using STATA command probit (logit) and includes country dummies. The ordered probit (logit) in Panel B uses STATA command xtprobit (xtlogit) without country dummies. Standard errors clustered at country level are in parentheses. ${ }^{*} p<0.10,{ }^{* *} p<0.05,{ }^{* * *} p<0.01$. 
capital structure and for the presence of capital controls. These data patterns suggest that a good institutional quality may enable a country to obtain more equity-like financing which reduces the probability of crises. With more risk sharing and more financial stability, there is less need for the country to impose capital controls.

\section{Benchmark Model}

We now develop a model of composition of capital flows that will match the salient empirical patterns documented in the previous section. We start with a discussion on how international equity and debt investors may have different degrees of vulnerability to institutional weakness of a capital-recipient country. Such difference can be represented by a parameter in a three-period model that generalizes Bianchi (2011) and Korinek (2018). We then characterize the optimal capital controls in such an economy.

\subsection{Institutional Quality and Expropriation}

Both equity and debt investors worry about expropriation risks in a capital recipient country. If a domestic agent (firm) on the receiving side of international capital flows misrepresents its true revenue or profit and gets away from it, it damages the interest of international investors. In order to cheat a foreign debt holder out of its rightful payoff, the CEO of the domestic firm needs to falsely declare a bankruptcy, which is likely to be very costly to the borrower. In comparison, in order to cheat a foreign equity shareholder a part of his rightful payoff, the domestic CEO only needs to overstate some of its cost items or understate some of its revenue items, which are less costly to implement and harder to detect than a fake bankruptcy. This suggests an important asymmetry between the two forms of capital flows: equity investment is more vulnerable to expropriation risks than debt investment.

To formalize this argument, let us consider a simple three-period endowment economy. The time periods are denoted by $t=1,2$ and 3 , respectively. There are two types of goods, tradable and non-tradable goods. To simplify the analysis, the non-tradable consumption 
only appears in the second period. ${ }^{6}$ The preference of domestic agents is given by

$$
\omega_{T} \log C_{T 1}+\beta E_{1}\left[\omega_{T} \log C_{T 2}+\omega_{N} \log C_{N 2}+\beta \omega_{T} \log C_{T 3}\right]
$$

where $\beta$ is the discount factor, $\omega_{T}\left(\omega_{N}=1-\omega_{T}\right)$ equals the share of tradable (non-tradable) consumption in the total spending on consumption, and $C_{T t}\left(C_{N 2}\right)$ is the tradable (nontradable) consumption at time $t=1,2,3$ (time 2).

Income Stream There is no income in the first period, and the income streams in the last two periods are given by $\left\{y_{2}, y_{N 2}, y_{3}\right\}$, respectively, where $y_{t}$ is the tradable income in pe$\operatorname{riod} t=2,3$ and $y_{N 2}$ is the non-tradable income in period 2. By construction, the first period consumption has to be financed externally, by either selling an equity claim on the tradable goods in the second and the third periods, selling a bond, or a combination of the two. (The domestic agent does not buy foreign equity, but it is possible that she buy foreign bonds but sells a domestic equity claim simultaneously.) We assume that only $y_{2}$ is stochastic and is uniformly distributed in $U[\underline{y}, \bar{y}]$ with $\underline{y}>0$.

Debt and Equity Contracts To facilitate analysis on expropriation risk, we assume that there are two types of domestic agents with a unit measure: a representative household and many CEOs. Each CEO manages one firm which generates an exogenous income stream $\left\{y_{2}, y_{N 2}, y_{3}\right\}$. A CEO can issue either equity or debt contracts (or both) in the first period at unit price of $p_{e}$ and $p_{d}$ respectively, and then distribute the money back to the household. We assume that while the CEOs might cheat foreign investors, they cannot cheat domestic households. Moreover, the CEOs are risk neutral even though the representative household is risk averse. Letting the CEOs solve the same problem as the household will not alter the qualitative results, but will add some expositional complications.

Foreign investors purchase $s$ shares of equity from the country at price $p_{e} s$ in $t=1$ in exchange for a future tradable income stream $\left\{s y_{2}, s y_{3}\right\}$ in $t=2$ and $t=3$ respectively. $^{7}$ By doing so, the equity contract provides risk-sharing between the home country and inter-

\footnotetext{
${ }^{6}$ The role of the non-tradable good is to provide a relative price between the two goods, which enters into the collateral borrowing constraint. Since the borrowing constraint is assumed to only appear in period 2, it is innocuous for the non-tradable good consumption to occur only in period 2.

${ }^{7}$ The equity contract is a claim only on the tradable income.
} 
national investors. The international investors, however, can also purchase $d$ units of debt from the country with a price $p_{d} d$ at time $t=1$ in exchange for a promised fixed payment $d$ at period 2. The prices of both equity and debt are in units of the tradable good. In the intermediate period $(t=2)$, the country can also roll over its debt that will be repaid in period $t=3$. As will be explained below, this external financing at time 2 is subject to a collateral borrowing constraint as in the literature (e.g. Korinek (2018)).

Financial Frictions Following Bianchi (2011) and Korinek (2018), There are frictions to roll over the short-term debt in period 2. In particular, the domestic agent can only pledge a fraction $\phi \in[0,1]$ of its period-2 income stream to international investors. Therefore, the maximum amount of debt issued in period 2 cannot exceed the collateral value as follows. ${ }^{8}$

$$
\frac{d^{\prime}}{1+r} \leq \phi\left[p y_{N 2}+(1-s) y_{2}\right]
$$

where $d^{\prime}$ is the quantity of roll-over debt in period 2, $r$ is a world risk-free rate, $p$ is the price of non-tradable good, and $s \in[0,1]$ is the share issued in period $1 .^{9}$

The existence of a collateral borrowing constraint (2) has both positive and normative implications. As suggested by the literature, it is a good way to capture financial crises (see Mendoza (2010) and Bianchi (2011)). In this economy, a binding constraint is characterized as an occurrence of a crisis. It also provides a rationale for policy intervention since it involves a pecuniary externality, which will be explained later (see Korinek (2018) and Dávila and Korinek (2018)).

Institutional Quality and Payoff Manipulation To capture the effect of institutional quality, we highlight possible manipulation of the security payoffs by domestic agents (the CEOs) after issuance. ${ }^{10}$ For example, a CEO can pretend that his firm's income stream is

\footnotetext{
${ }^{8}$ Here the domestic CEO can only pledge $p y_{N 2}+(1-s) y_{2}$ period-2 income stream after selling $s$ share of tradable income. Alternatively, if the CEOs can pledge all period-2 income $p y_{N 2}+y_{2}$, the results are quantitatively similar.

${ }^{9}$ Following Korinek (2018), we use the actuarially fair price $\frac{1}{1+r}$ for the roll-over debt in period 2. As will be shown later, this is consistent with the price of debt $p_{d}$ in period 1 when the bankruptcy cost is sufficiently large. We do not differentiate between passive equity and FDI here and do not allow the agents to issue equity in period 2. These assumptions will be relaxed in Section 5 and Online Appendix E, respectively.

${ }^{10}$ There is asymmetric information between the CEO and foreign investors, but not between the CEO and
} 
only $\left\{(1-\kappa) y_{2},(1-\kappa) y_{3}\right\}$ with $\kappa \in[0,1]$ when the true income stream is $\left\{y_{2}, y_{3}\right\}$. Such a behavior is costly to the $\mathrm{CEO}$ as there is a chance that the international investors may discover the true payoff and convince the local court to punish the CEO. In this case, the CEO has to pay a fine of $\left\{\chi y_{2}, \chi y_{3}\right\}$ to the investor with $\chi \in(\kappa, 1]$. We denote the probability that the international investors fail to recoup what they are due by $q \in[0,1]$. The probability $q$ reflects the inverse of the quality of domestic institution. With a higher value of $q$, international investors will have greater difficulty not only to discover the misdeed of the CEO, but also to find an impartial local court to win the case. A higher value of q can also mean poorer corporate accounting standard or more corruptible local judges.

The domestic CEO can also manipulate the payoff to international debt holders by falsely claiming an inability to pay back the debt and declaring bankruptcy. We denote the bankruptcy cost by $B$ for each unit of debt contract. In bankruptcy, the CEO can reduce each unit of debt contract's payment from 1 to $1-\kappa^{\prime}$ with $\kappa^{\prime} \in[0,1]$. Without loss of generality, we assume that the probability for the international debt holders to suffer a loss in an event of bankruptcy is also given by $1-q$. Once they win in the court, the penalty on the domestic CEO is given by $\chi^{\prime}$ with $\chi^{\prime} \in\left(\kappa^{\prime}, 1\right]$.

International Investors There is a continuum of risk neutral international investors who have access to a storage technology with a return $r>0$. They will price the equity contract and debt contract by taking into account the possibility of payoff manipulation in the capital-recipient country. In particular, there will be a discount in the actuarially fair price reflecting the degree of manipulation. For example, denote the actuarially fair prices for debt and equity by $\frac{1}{R} \equiv \frac{1}{1+r}$ and $y_{1}=\frac{\frac{y+\bar{y}}{2}+\frac{y_{3}}{1+r}}{1+r}$ respectively. The expected fractions of income deduction once domestic agents manipulate equity and debt payoffs are thus given by $[q \kappa-(1-q) \chi]$ and $\left[q \kappa^{\prime}-(1-q) \chi^{\prime}\right]$ respectively. Use an indicator function $\mathbb{1}$ to capture the decisions by the domestic agents to manipulate the equity or debt payoff, i.e. $m_{e}=1$

the household. 
and $m_{d}=1$ respectively. The prices $p_{e}$ and $p_{d}$ will then be given as follows.

$$
\begin{aligned}
p_{e} & =\frac{E\left[y_{2}+\frac{y_{3}}{1+r}-\mathbb{1}_{m_{e}=1}[q \kappa-(1-q) \chi]\left(y_{2}+\frac{y_{3}}{1+r}\right)\right]}{1+r} \\
& =y_{1}\left(1-\frac{[q \kappa-(1-q) \chi] E\left[\mathbb{1}_{m_{e}=1}\left(y_{2}+\frac{y_{3}}{1+r}\right)\right]}{y_{1}(1+r)}\right) \\
p_{d} & =\frac{E\left[1-\left[q \kappa^{\prime}-(1-q) \chi^{\prime}\right] \mathbb{1}_{m_{d}=1}\right]}{1+r}
\end{aligned}
$$

Incentive to Manipulate Security Payoffs The domestic agent (CEO) chooses whether to manipulate the securities' payoffs at the beginning of period 2. Intuitively, the net benefit of manipulating equity payoff is the expected fraction of the present value of promised cash flows, $q \kappa-(1-q) \chi$. As long as the net benefit is non-negative, domestic agents find it profitable to manipulate the equity payoff. However, the net benefit for manipulating debt payoff, $q \kappa^{\prime}-(1-q) \chi^{\prime}$ has to be higher than a bankruptcy cost $B$. Otherwise, it is not worthwhile to manipulate debt payoffs. The decision is given by Proposition 1 .

Proposition 1. The incentive for domestic agents to manipulate payoffs depends on parameter values. Specifically,

- CEO's payoff from cheating equity investors are given by $[q \kappa-(1-q) \chi] y_{1}$. She does not manipulate equity payoffs when $q<\frac{\chi}{\kappa+\chi}$ but does so when $q \geq \frac{\chi}{\kappa+\chi}$.

- CEO's payoff from cheating debt investors are given by $q \kappa^{\prime}-(1-q) \chi^{\prime}-B$. She does not manipulate debt payoffs when $q<\frac{\chi^{\prime}+B}{\chi^{\prime}+\kappa^{\prime}}$ but does so when $q \geq \frac{\chi^{\prime}+B}{\chi^{\prime}+\kappa^{\prime}}$.

When the domestic institutional quality is high, the probability for investors to lose (unfairly) in the court will be low, i.e. $q$ is likely to be low. When it is sufficiently low such as below a threshold $\frac{\chi}{\kappa+\chi}$, domestic agents never manipulate equity payoff in equilibrium. The equity is thus priced at its actuarially fair price. However, when the institutional quality is not high enough, i.e. $q$ is above the threshold, domestic agents will always manipulate the equity payoffs. As a result, the equity is priced at a discount which reflects the degree of domestic institutional quality. We can introduce a parameter $\theta \equiv \max \{0, q \kappa-(1-q) \chi\}$ 
to capture such a discount. In this case, equity price can be written as

$$
p_{e}=(1-\theta) y_{1}
$$

The difference in the incentives to manipulate equity and debt payoffs lies in the bankruptcy $\operatorname{cost} B$. For the domestic agents to manipulate debt payoffs, the probability $q$ has to be a higher threshold than that for equity, i.e. $q \geq \frac{\chi^{\prime}+B}{\chi^{\prime}+\kappa^{\prime}}$. Therefore, the debt price also reflects the degree of domestic institutional quality. In our analysis, we focus on the case where $B>\kappa^{\prime}$, i.e. the bankruptcy cost is sufficiently high. In this case, domestic agents never find it optimal to manipulate debt payoffs. In equilibrium, the price of debt is at its actuarially fair level, i.e. $p_{d}=\frac{1}{1+r}$.

Interpretation of Institutional Quality In our model, $\theta$ captures the expected loss for the equity payoffs in the perspective of international investors. Such a loss is generated by the mis-behavior of domestic agents, such as firms (CEOs) or corruptible judges. This sub-section can be viewed as a micro-foundation for $\theta$ as an expropriation risk.

If we think broadly, $\theta$ as an expropriation risk can also result from actions by government officials. Good institutions can be thought of as strong restraint on expropriation (the risk of having private property taken by the government or a well-connected private party without compensation or a just clause). In either case, the level of expropriation risk matters for the willingness of foreign investors to provide financing.

In the following analysis, we use $\theta$ as a measure for institutional quality and push the manipulation of the security payoff into the background. This expropriation risk will be reflected in the households' budget constraints as well. In each period, the CEOs make the financing decision and then deliver the money receipts to domestic households. But if a CEO decides to cheat on foreign investors, he would keep the stolen payoff rather than delivering it to the household. ${ }^{11}$

In this case, domestic agents sell equity $s \in[0,1]$ and debt $d$ to finance their period1 consumption $C_{T 1}$. At period 2, they decide their tradable consumption $C_{T 2}$ and nontradable consumption $C_{N 2}$ at the market price of non-tradable good $p$. Their income stream

\footnotetext{
${ }^{11}$ We make this assumption for simplicity. Alternatively, we can let the stolen payoff to be distributed to the household in a lump-sum fashion. The results are similar.
} 
is $\left\{y_{2}, y_{N 2}\right\}$ in net of promised equity and debt repayment. They can also issue a roll-over debt $d^{\prime}$ to finance the difference subject to the collateral borrowing constraint. At time 3 , private agents choose consumption $C_{T 3}$ after repaying debt $d^{\prime}$ and equity $s y_{3}$. All the budget constraints for private agents are thus given by

$$
\begin{aligned}
& C_{T 1}=s y_{1}(1-\theta)+\frac{d}{1+r}, \\
& p C_{N 2}+C_{T 2}=p y_{N 2}+(1-s) y_{2}-d+\frac{d^{\prime}}{1+r}, \\
& C_{T 3}+d^{\prime}=(1-s) y_{3} .
\end{aligned}
$$

\subsection{Competitive Equilibrium}

The competitive equilibrium is defined as an allocation $\left\{s, d, d^{\prime}, C_{T 1}, C_{T 2}, C_{T 3}, C_{N 2}\right\}$, the price of non-tradables $p$ and the prices of equity and debt $\left\{p_{e}=(1-\theta) y_{1}, p_{d}=\frac{1}{1+r}\right\}$ that maximize the utility function (1) subject to the budget constraints, financial constraint (2) and a market clearing condition for non-tradable good, i.e. $C_{N 2}=y_{N 2}$.

\section{Period-2 Equilibrium}

It is convenient to define a liquid net worth at the beginning of period 2 as $m=(1-s) y_{2}-d$. The competitive equilibrium can be solved using backward induction. The maximization problem can be written as

$$
\begin{aligned}
V\left(m, s, y_{2}\right)= & \max _{C_{N 2}, C_{T 2}, C_{T 3}, d^{\prime}} \omega_{T} \log C_{T 2}+\omega_{N} \log C_{N 2}+\beta \omega_{T} \log C_{T 3}, \\
& \text { s.t. }(2),(4),(5) .
\end{aligned}
$$

Consistent with the existing literature, at the beginning of period 2, two states are possible, depending on the state variables $\left\{m, s, y_{2}\right\}$, where $m=(1-s) y_{2}-d$ is the net worth. In the good state, the financial constraint is slack and the economy can borrow to smooth consumption between periods 2 and 3. In the bad state, the financial constraint binds and the economy cannot borrow enough to smooth consumption. The realization of a bad state depends on the external financing decision in period 1. 
Proposition 2. The financial constraint binds if and only if the debt to income ratio $\frac{d}{1-s}$ exceeds some threshold, i.e.

$$
\frac{d}{1-s}>\frac{y_{2}\left(\frac{\beta}{1+\beta}+\frac{\phi / \omega_{T}}{1-\phi \frac{\omega_{N}}{\omega_{T}}}\right)-\frac{y_{3}}{(1+\beta)(1+r)}}{\frac{\beta}{1+\beta}+\frac{\phi \frac{\omega_{N}}{\omega_{T}}}{1-\phi \frac{\omega_{N}}{\omega_{T}}}}
$$

Proof. The proof is given in Appendix F.1

The intuition for Proposition 2 is consistent with the literature. When the country issues too much debt $d$ relative to its income stream share $1-s$, it has a lower net worth at the beginning of the period. Compared to the previous literature, issuing too much equity $\mathrm{s}$ can also lead to a lower net worth $m$. Yet, as will be shown later, equity issuance provides better risk-sharing opportunities.

\section{Period-1 Equilibrium: the Capital Structure}

At time 1, the representative private agent chooses the capital structure $\{s, d\}$ of its external financing to solve the following problem.

$$
\begin{aligned}
& W_{1}=\max _{s \in[0,1], d} \omega_{T} \log C_{T 1}+\beta E_{1}\left[V\left(m, s, y_{2}\right)\right], \\
& \text { s.t. } C_{T 1}=s y_{1}(1-\theta)+\frac{d}{1+r}, m=(1-s) y_{2}-d .
\end{aligned}
$$

The first-order conditions for debt and equity are

$$
\begin{aligned}
& \frac{\omega_{T}}{C_{T 1}}=\beta(1+r) E_{1}\left[V_{m}\right] \\
& \frac{\omega_{T}}{C_{T 1}} y_{1}(1-\theta)=\beta E_{1}\left[y_{2} V_{m}-V_{s}\right]
\end{aligned}
$$


where $V_{m}=\frac{\partial V\left(m, s, y_{2}\right)}{\partial m}$ and $V_{s}=\frac{\partial V\left(m, s, y_{2}\right)}{\partial s} \cdot{ }^{12}$

The economic interpretation is straightforward. Private agents equate the marginal benefit of debt (equity) with its marginal cost. To better understand the trade-off, we start from an extreme case where there is no expropriation risk, i.e. $\theta=0$. As we show below, the country will choose to sell all of its future tradable income since equity allows full risk-sharing between the country and international investors.

Given that an equity contract allows the country to sell off all its (risky) income in exchange for a certain income stream without any efficiency loss, the economy prefers to do so. International investors are indifferent since they are risk-neutral. Therefore, the equity contract can achieve full risk-sharing between the country and international investors. The following proposition summarizes the intuition.

Proposition 3. When there is no expropriation risk, i.e. $\theta=0$, the agent chooses (and obtains) $s=1$ in order to achieve full insurance, i.e. the first best allocation.

Proof. The proof is given in Appendix F.2.

Proposition 3 suggests that the advantage of equity over debt financing is to provide better risk-sharing. When there is no additional cost for equity issuance, the private agent in the country prefers to issue equity over debt. However, in general, a positive expropriation risk $\theta>0$ raises the equity issuance cost. This presents a trade-off between equity and debt financing. On the one hand, equity financing provides better risk-sharing; On the other hand, the expropriation risk reduces the present value of future income stream, causing investors to apply a discount to the equity price. The equilibrium structure of capital financing reflects a balance between these two forces. The following proposition establishes an equilibrium capital structure in this economy.

Proposition 4. The equilibrium capital structure reflects the degree of expropriation risk $\theta$.

\footnotetext{
${ }^{12}$ The optimality condition for equity is for the interior solution. For the corner solutions, we have

$$
\begin{aligned}
& \frac{\omega_{T}}{C_{T 1}} y_{1}(1-\theta)-\beta E_{1}\left[y_{2} V_{m}-V_{s}\right]>0, \text { if } s=1 . \\
& \frac{\omega_{T}}{C_{T 1}} y_{1}(1-\theta)-\beta E_{1}\left[y_{2} V_{m}-V_{s}\right]<0, \text { if } s=0 .
\end{aligned}
$$
}


1. When the quality is sufficiently good, i.e. $\theta<\underline{\theta}$, there will be only equity issuance.

2. When the quality is sufficiently poor, i.e. $\theta>\bar{\theta}$, there will be only debt issuance.

3. When $\theta \in(\underline{\theta}, \bar{\theta})$, there will be a combination of equity and debt. As the cost of issuing equity $\theta$ increases, the country chooses a higher level of debt $d$, a lower share of equity $s$, and a higher leverage, $\frac{d /(1+r)}{s(1-\theta) y_{1}+d /(1+r)}$. This will result with a more binding collateral constraint in the second period, i.e. a higher probability of crises.

Proof. The proof is given in Appendix F.3.

\subsection{Optimal Capital Controls}

In general, an economy with incomplete markets and pecuniary externalities may have sub-optimal allocations (see Geanakoplos and Polemarchakis (1986) and Greenwald and Stiglitz (1986)). This opens up a role for policy intervention. The existence of pecuniary externality in our context is due to the collateral borrowing constraint, resulting in a vicious cycle of "lower price - more binding constraint - asset sale - lower price". Intuitively, when the collateral constraint binds, the private agent cuts spending. With a decline in the aggregate spending, the price of non-tradable goods falls, which leads to even lower income of other agents, precipitating further deleveraging in the economy. In deciding how much financing in Period 1 to obtain from international investors, private agents do not take into account the effect of their actions on other agents' income and on this vicious cycle. In this sense, they borrow too much (relative to a socially efficient level).

What would a social planner do to correct this externality if she cannot remove collateral constraint directly? She can internalize the general equilibrium effect through the price of non-tradable good in the aggregate borrowing constraint. Below, we compare the allocation chosen by the social planner with the one that arises from competitive equilibrium. 
The social planner solves the following maximization problem.

$$
\begin{aligned}
W_{1}^{S P}=\max _{d, s \in[0,1]} & \omega_{T} \log C_{T 1}+\beta E_{1}\left[V^{S P}\left(m, s, y_{2}\right)\right] \\
\text { s.t. } & C_{T 1}=s(1-\theta) y_{1}+\frac{d}{1+r}, \\
& m=(1-s) y_{2}-d .
\end{aligned}
$$

where $V^{S P}\left(m, s, y_{2}\right)$ is given by

$$
\begin{aligned}
V^{S P}\left(m, s, y_{2}\right)= & \max _{C_{T 2}, C_{T 3}, d^{\prime}} \omega_{T} \log C_{T 2}+\omega_{N} \log y_{N 2}+\beta \omega_{T} \log C_{T 3} \\
& \text { s.t. } C_{T 2}=m+\frac{d^{\prime}}{1+r} \\
& \frac{d^{\prime}}{1+r} \leq \phi\left(\frac{\omega_{N}}{\omega_{T}} C_{T 2}+(1-s) y_{2}\right) \\
& C_{T 3}+d^{\prime}=(1-s) y_{3}
\end{aligned}
$$

It is straightforward to see that the competitive equilibrium displays constrained inefficiency as it differs from the allocation chosen by the social planner.

Proposition 5. The social planner values the net worth $m=(1-s) y_{2}-d$ more than private agents, i.e. $\frac{\partial V^{S P}\left(m, s, y_{2}\right)}{\partial m}>\frac{\partial V\left(m, s, y_{2}\right)}{\partial m}$.

Proof. The proof is given in Appendix F.4.

While the social planner cannot change the allocation in Period 2, she values the net worth at the end of the first period more than the private agents, and would therefore choose a lower level of external financing in Period 1. She would discourage the private agents from issuing too much debt or equity since both create a pecuniary externality.

Proposition 6. There exists three thresholds for institutional quality as shown in Figure 2, $\underline{\theta}^{S P}<\theta^{*}<\bar{\theta}^{S P}$

- When the institutional quality is sufficiently good, i.e. $\theta<\underline{\theta}^{S P}$, there will be only equity issuance and the economy is constrained efficient. 
Figure 2 CAPITAl Structure And EfFiciency: An Illustrative Graph

\section{Capital Structure}

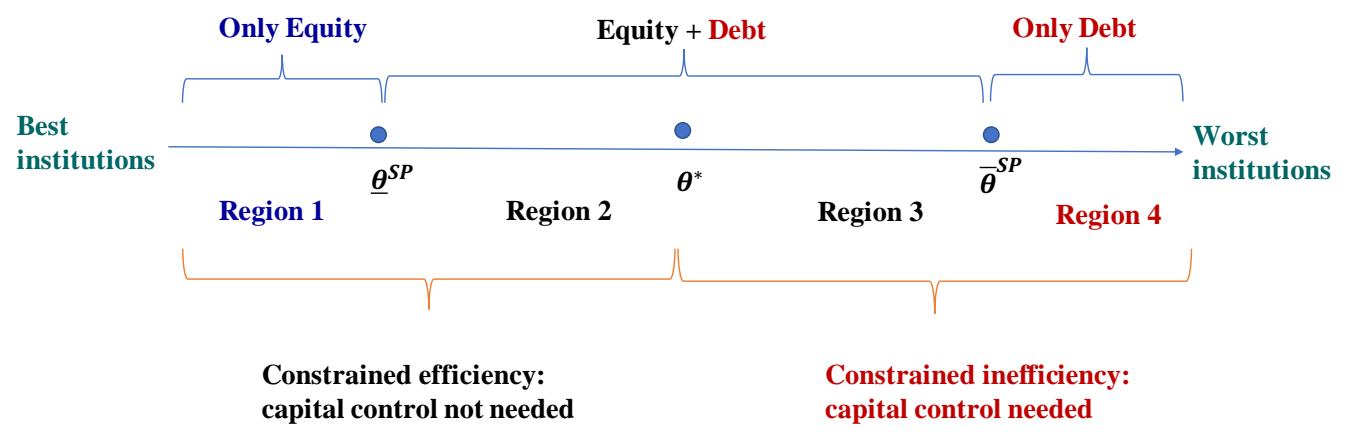

Public Policy

- When $\theta \in\left(\underline{\theta}^{S P}, \bar{\theta}^{S P}\right)$, there will be a mixture of equity and debt. As the cost of issuing equity $\theta$ increases, the country chooses a higher level of debt $d$, a lower share of equity $s$, and a higher leverage, $\frac{d /(1+r)}{s(1-\theta) y_{1}+d /(1+r)}$, and experience a greater likelihood of a binding constraint in the second period.

- When the quality is sufficiently poor, i.e. $\theta>\bar{\theta}^{S P}$, there will be only debt financing.

- The competitive equilibrium is constrained efficient if and only if $\theta<\theta^{*}$. Compared to the private agents, the social planner chooses both a lower level of total external financing and a lower level of leverage $\frac{d}{1-s}$.

Proof. The proof of Proposition 6 is given in Appendix F.5.

The optimal capital structure chosen by the social planner strikes a balance between debt and equity financing. The key determinant is the expropriation risk, $\theta$. The difference between the private agents and the social planner depends on the size of the pecuniary externality. To internalize the externality, the social planner does two things. First, she chooses less external financing, resulting in a higher level of net worth in the second period. Second, she chooses a less risky capital structure featuring a lower debt-to-equity ratio. 
Proposition 6 points to the importance of institutional quality. By reducing $\theta$ below a threshold $\theta^{*}$, the economy converges to a constrained efficient world. Even if the first-best allocation cannot be achieved due to the distortions in equity issuance cost, the economy is free of financial crises. On the other hand, if institutional reforms cannot be obtained in the short run, optimal capital controls have to be deployed to reduce financial vulnerability.

Implementation To implement the social planner's allocation, a Pigovian taxation approach can be deployed. In particular, the social planner would use a vector of capital control taxes $\left\{\tau^{s}, \tau^{d}\right\}$ on equity and debt, together with a lump-sum transfer $T$. The budget constraint of the private agents changes into

$$
C_{T 1}=\left(1-\tau^{s}\right) s(1-\theta) y_{1}+\left(1-\tau^{d}\right) \frac{d}{1+r}+T
$$

where $T=\tau^{s} s(1-\theta) y_{1}+\tau^{d} \frac{d}{1+r}$.

Proposition 7. To implement the social planner's allocation, a pair of capital control taxes $\left\{\tau^{s}, \tau^{d}\right\}$ on external equity and debt is needed:

$$
\begin{aligned}
\tau^{d} & =\frac{\beta(1+r) E\left[\phi \mu \frac{\omega_{N}}{\omega_{T}}\right]}{\frac{\omega_{T}}{C_{T 1}}}>0 \\
\tau^{s} & =\frac{\beta E\left[\phi \mu \frac{\omega_{N}}{\omega_{T}} y_{1}\right]}{\frac{\omega_{T}}{C_{T 1}}(1-\theta) y_{1}}>0
\end{aligned}
$$

Furthermore, $\tau^{d}>\tau^{s}$.

Proof. The proof is given in Appendix F.5.

It may appear surprising that the optimal tax on equity is positive when institutional quality is low even though equity financing provides better risk-sharing than debt. To see the intuition, note that selling equity shares in Period 1 also lowers the net worth in period 2 (as $m=(1-s) y_{2}-d$ ). If there is a tax on debt but no tax on equity financing, the agents will issue more equity than desired by the social planner. In other words, when the institutional quality is low, the externality in the debt market financing spills over to equity financing. 
As the social planner values the end-of-period-1 net worth more than the private agents, she corrects this spillover problem by imposing positive taxes on both equity and debt.

We also note that the debt embeds more externality than equity financing. As a result, the optimal policy features a higher tax rate on debt than on equity financing. This theoretical prediction is consistent with the practice of capital controls by the Brazilian government during 2008-2013, when a higher tax on portfolio debt relative to that on equity was imposed. It is consistent with the "pecking order" theory of capital controls proposed by Ostry et al. (2010), where controls are first imposed on foreign debt and then on portfolio equity (see Forbes et al. (2016) and Chamon and Garcia (2016)).

The capital control decision made by a bureaucrat can in principle differ from a social planner's choice, but they would still be related. In the theory of tariff determination by Grossman and Helpman (1994), the politician is assumed to maximize a convex combination of private benefits and social welfare. In a celebrated empirical estimation of the Grossman and Helpman (1994) model, Goldberg and Maggi (1999) find that the empirical weight on the social welfare is in excess of 90 per cent. Similar results are found for other countries as well. If one were to write down a political economy model on capital control taxes, the comparative statics with respect to institutional quality is likely to be similar to the social planner's choice, even though the levels of the taxes would be different.

\section{$4 \quad \theta$ Versus $\phi$ : A Comparison by Examples}

In our theory, the parameter for institutional quality, $\theta$, plays a crucial role. It is natural to wonder whether variations in another parameter, the degree of collateral constraint, $\phi$, can generate the same predictions. Indeed, in the existing literature on sudden stops, one is tempted to think that the main difference between developing and developed countries is in the degree of collateral constraint.

We now compare the two parameters by a series of simulations. We will show that either an improvement in the institutional quality or a relaxation of the collateral constraint will result in a lower probability of crises. However, there are two key differences. First, while an improvement in institutions leads to a higher share of equity financing in a country's external liabilities, an opposite pattern is associated with a more relaxed collateral 
constraint. Second, while countries with better institutions need less capital control, countries with a more relaxed collateral constraint need more capital control. Bianchi (2011) also reports that the optimal tax on capital flows becomes higher, in his simulation (Panel $\mathrm{C}$ of Figure 6 in his paper), when a country's collateral constraint is relaxed.

We conduct our simulations in two steps. First, we hold the degree of collateral constraint $\phi$ constant (at the same benchmark value as in Bianchi (2011)) and vary the values of $\theta$. This is equivalent to numerically simulate the theoretical predictions from the previous section, with the aim of providing further intuition. Second, we re-do the exercise by picking different values of $\phi$. This can be understood as a numerical comparative statistics exercise over changes in the degree of collateral constraint.

\subsection{Variations in $\theta$}

The parameter values chosen for the simulation exercises are reported in Table C.3. For the share of tradable expenditure in total consumption spending, we choose $30 \%$ following Bianchi (2011). The risk-free interest rate is chosen to be 5\%, a common value used in the literature. We assume that the discount rate, $\beta$, is the inverse of $1+r$. The collateral constraint value $\phi$ is chosen to be 0.3 in the baseline case, meaning that the country can only pledge $30 \%$ of its current income to international investors (see Ma (2020)). For period2 income $y_{2}$, we use a uniform distribution in $U\left[\bar{y}_{2}-\varepsilon, \bar{y}_{2}+\varepsilon\right]$, with a mean of $\bar{y}_{2}$ and $\varepsilon$ governing its income risk. We vary the parameter denoting the expropriation risk, $\theta$, to see how it affects of the composition of capital flows and the gap in the allocations between the competitive equilibrium and the social planner's choice.

Figure 3 shows the optimal capital structure for different values of $\theta$. A lower level of $\theta$ implies a better institutional quality. Consistent with our theoretical prediction, when expropriation risk $\theta$ increases, the debt $d$ increases while the equity $s$ decreases. When $\theta$ rises up to a certain level, i.e. $\bar{\theta}^{C E}$ in the competitive equilibrium $\left(\bar{\theta}^{S P}\right.$ in the social planner's allocation), the cost of equity issuance is sufficiently high such that the share of equity goes to zero. The level of total external financing $C_{T 1}$ is also reduced with a higher $\theta$ because a higher equity issuance cost at the margin also increases the cost of debt financing and thus the overall marginal cost of external financing. As a result, the economy takes on more leverage with a higher $\theta$. Such a riskier external capital structure leads to a higher 
Figure 3 OPTIMAL CAPITAL StRUCTURE

Panel A: Debt Financing $(d)$

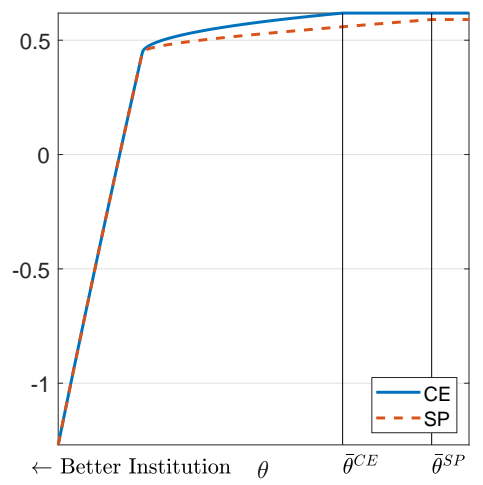

Panel C: Total External Financing $\left(C_{T 1}\right)$

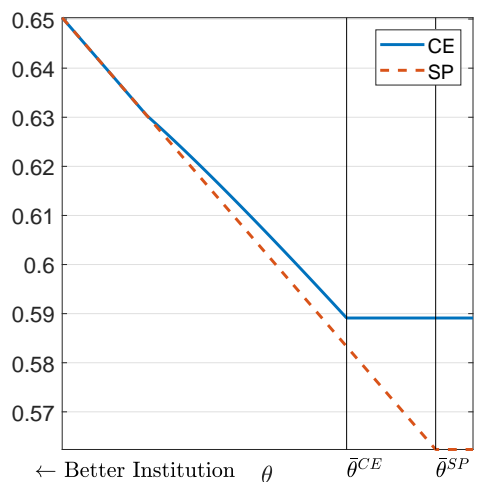

Panel B: Equity Financing $(s)$

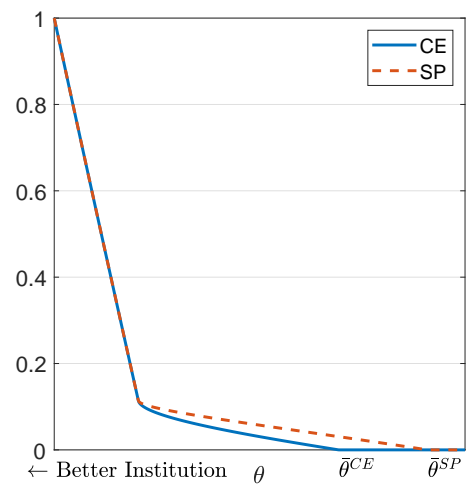

Panel D: Leverage $\left(\max \left\{\frac{d}{\frac{1+r}{C_{T 1}}}, 0\right\}\right)$

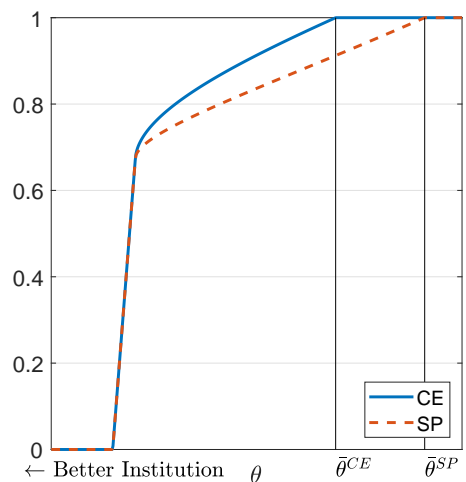

NOTE. This figure shows the comparative statistics by varying institutional quality parameter $\theta$, while keeping the values of all other parameters the same as in Table C.3. For a given value of $\theta$, we solve the model both in competitive equilibrium and with the social planner. We plot $d, s, C_{T 1}$, and $\left(\max \left\{\frac{d}{\frac{1+r}{C_{T 1}}}, 0\right\}\right)$ in Panels A, $\mathrm{B}, \mathrm{C}$, and $\mathrm{D}$, respectively, as a function of $\theta$.

probability of crises as shown in Panel A of Figure 4.

Relative to the private agents, the social planner chooses a lower level of external financing $\left(C_{T 1}\right)$ and a safer capital structure, i.e. lower leverage. In particular, she chooses a lower level of debt and a higher level of equity. Because the social planner prefers equity over debt, the threshold of the institutional quality above which the equity issuance converges to zero is higher for the social planner than for the private agents, i.e. $\bar{\theta}^{S P}>\bar{\theta}^{C E}$. 
Figure 4 FinANCIAL STABILITY AND WELFARE GAINS

Panel A: Probability of Crises

Panel B: Welfare Gains (\%)
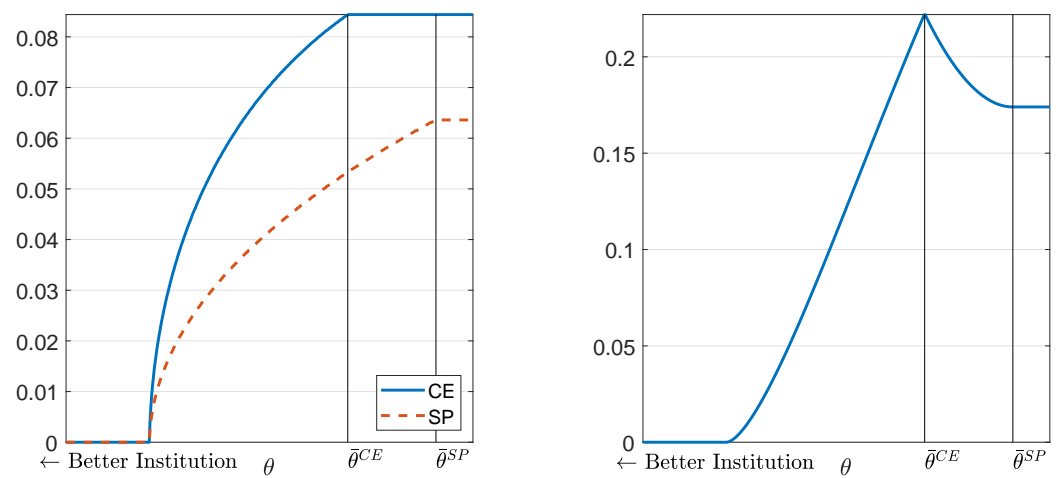

NOTE. This figure shows the comparative statistics by varying institutional quality parameter $\theta$, while keeping the values of all other parameters the same as in Table C.3. For a given value of $\theta$, we solve the model both in competitive equilibrium and with the social planner. We plot the probability of crises (defined as the frequency of binding constraint states in period 2) in Panel A and the welfare gains in Panel B (\%, defined as $100\left(e^{W^{S P}-W^{C E}}-1\right)$, where $W^{S P}$ and $W^{C E}$ are the welfare functions under the social planner and competitive equilibrium allocations, respectively).

Due to a less leveraged capital structure, the economy chosen by the social planner is safer than the one in the competitive equilibrium in terms of a lower probability of crises. This means that a policy intervention can raise the welfare. The greater the expropriation risk, $\theta$, the greater the welfare gains from the intervention. This is because the overleveraging problem becomes more severe when the expropriation risk rises. Indeed, when the expropriation risk exceeds some threshold i.e. $\theta \in\left[\bar{\theta}^{C E}, \bar{\theta}^{S P}\right]$, the private agents would find it too costly to issue equity and thus only issue debt in the competitive equilibrium. For comparison, the social planner prefers equity over debt and would continue to choose equity even with a higher equity issuance $\operatorname{cost}, \theta$. In this region, an increase in $\theta$ narrows the welfare gain because the cost of intervention increases with $\theta$. To summarize, the welfare gain from capital controls first increases with the extent of expropriation risk and then declines after a turning point at $\bar{\theta}^{C E}$.

Figure 5 shows the effects of the taxes on external equity and debt. Consistent with the theoretical prediction, both taxes increase with the expropriation risk $\theta$ due to increased inefficiency associated with the competitive-equilibrium capital structure. Furthermore, 
Figure 5 CAPITAL CONTROL TAXES (\%)

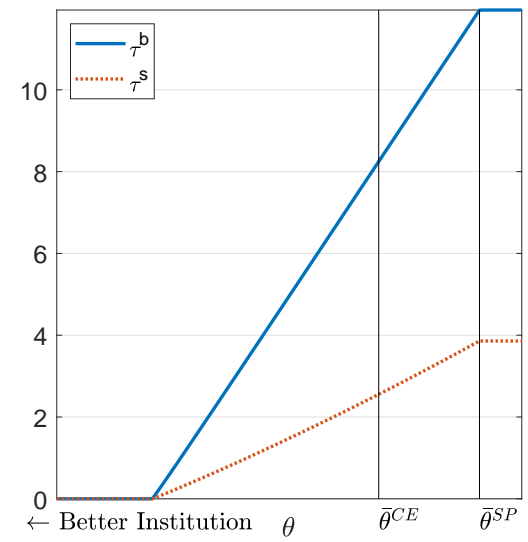

NOTE. This figure shows the comparative statistics by varying institutional quality parameter $\theta$ (while keeping all other parameter values the same as in Table C.3). For a given value of $\theta$, we solve the model in competitive equilibrium and with the social planner, respectively. We plot the capital controls taxes defined in Proposition 7 as a function of $\theta$.

the optimal capital control tax on debt is larger in magnitude than that on equity. The total capital control tax on external debt varies from 0 to $12 \%$, which is comparable to the numbers in Bianchi (2011). The optimal tax on external equity is between 0 to $4 \%$, which is consistent with the policy rates on portfolio equity observed empirically (see Forbes et al. (2016) and Chamon and Garcia (2016)).

\subsection{Variations in $\phi$}

We now simulate comparative statics with respect to $\phi$ by picking two different values of $\phi$ to describe two different degrees of collateral constraint. In Panels A, B and C of Figure 6 , we present debt financing, equity financing and probability of crises as a function of $\theta$ under the two values of collateral constraint. The blue lines correspond to a looser collateral constraint $(\phi=0.3)$ while the red lines correspond to a tighter borrowing constraint $(\phi=$ 0.2 ). The solid lines describe the competitive equilibrium while the dashed lines correspond to the social planner's choice. In panel D, the capital control taxes on debt (the solid lines) and equity (the dashed lines) are presented for the case of a tight collateral constraint 
Figure 6 COMPARATIVE STATISTICS ABOUT $\phi$

Panel A: Debt Financing $(d)$

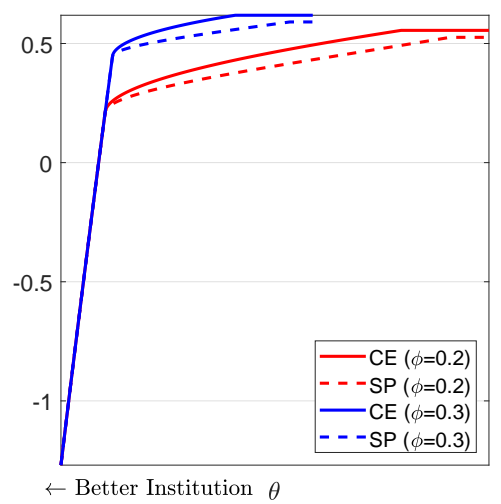

Panel C: Probability of Crises

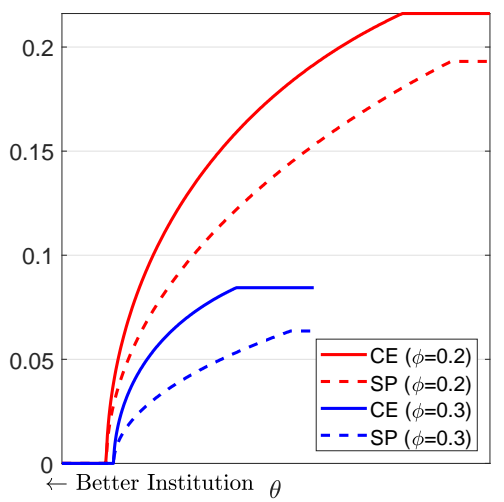

Panel B: Equity Financing $(s)$

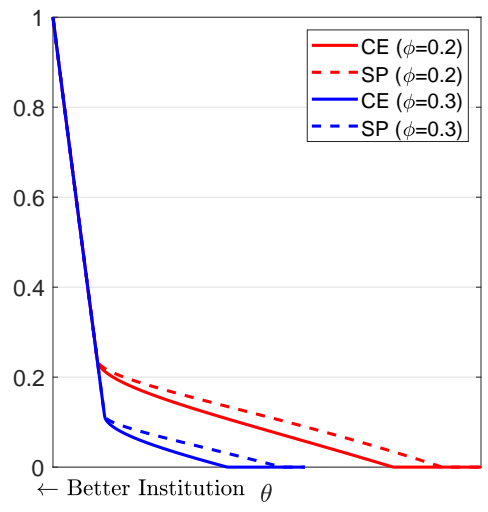

Panel D: Capital Control Taxes (\%)

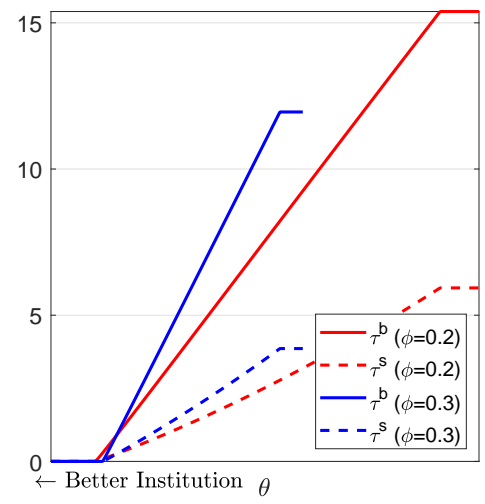

Note. This figure shows the comparative statistics with respect to institutional quality parameter $\theta$ under two values $\phi$ of collateral constraint. $\phi=0.2$ (all the red lines) is a case of a relatively tight collateral constraint, whereas $\phi=0.3$ (all the blue lines) is a case of a less tight collateral constraint. For each value of $\phi$ and $\theta$, we solve the model both in competitive equilibrium and with the social planner. We plot $d$, $s$, the probability of crises (defined as the frequency of binding constraint states in period 2), and the optimal capital control taxes (defined in Proposition 7) in Panels A, B, C, and D, respectively.

(marked in red when $\phi=0.2$ ) and the case of a less tight collateral constraint (marked in blue when $\phi=0.3)$, respectively.

From the comparative analyses, one can observe an interesting pattern. With sufficiently good institutions (i.e., a low value of $\theta$ ), the two different degrees of collateral constraint do not make a difference. Intuitively, when the institutional quality is high enough, 
equity financing will be sufficiently high, and the collateral constraint does not bind. As a result, there is no inefficiency for either value of $\phi$, and there is no need for capital controls.

When the institutional quality is below a threshold (i.e., when $\theta$ is above a threshold), the competitive equilibrium not only produces too much debt relative to the social optimum, but the over-borrowing is more severe under a less tight collateral constraint (solid blue in Panel A) than under a tighter collateral constraint (solid red in Panel A). This can be seen most clearly in Panel D where the optimal tax on debt inflow is higher when the collateral constraint is less tight (i.e., the solid blue line is above the solid red line).

Unsurprisingly, a looser collateral constraint generates a lower equity share (i.e., the solid blue line lies below the solid red line in Panel B) and a lower probability of crisis (i.e., the solid blue is below the solid red line in Panel C). However, by reducing the cost of debt financing, this at the margin increases debt and reduces equity in the first period.

From Panel D, an interesting pattern is that the social planner would impose higher taxes on both equity and debt when the collateral constraint is less tight. In other words, at a given level of institutional quality $\theta$ (when it is worse than a threshold), the competitive equilibrium produces both more excess equity issuance and more excess borrowing when the collateral constraint becomes looser, and the increases on these two margins call for an increase in the capital control tax on both capital flows. Not only is there a spillover of the externality from debt financing to equity financing, but the spillover could become worse as the collateral constraint relaxes.

Intuitively, the wedge between the social and private values of the end-of-period-one wealth is related to the expected social cost of a financial crisis, which can be decomposed into the probability of a crisis and the severity of a crisis. While a relaxation of the collateral constraint (a higher $\phi$ ) lowers the probability of a crisis, it raises the leverage ex-ante and raises the severity of a crisis. The net effect depends on the relative strength of the two forces. In our simulations, for most values of $\theta$, the second effect dominates.

To summarize, financial development and institutional improvement are not equivalent in terms of their effects on the composition of capital flows and on the wedge between the social planner's choice and the competitive equilibrium. In Bianchi (2011)'s simulation reported in Panel C of his Figure 6, the optimal tax on debt needs to go up rather than down when the collateral constraint is relaxed. We find the same pattern in our simulation. In addition, we find that the social planner would generally imposes a tax on both equity 
and debt flows, and the optimal levels of the two taxes tend to go up when the collateral constraint is relaxed.

Economic development may be associated with both a higher institutional quality and a more relaxed collateral constraint. Since more developed countries tend to have both a higher equity share in their external liabilities and fewer capital controls, such patterns can be easily reconciled in our model with better institutional quality, but not with a more relaxed collateral constraint. In other words, to understand cross-country differences in capital flow composition and capital controls, institutional quality may be more important than the degree of collateral constraint.

\section{Model Extensions}

We discuss three extensions to the baseline model. In the first one, we allow for both passive equity and FDI. In the second one, we introduce long-term debt. In the third one, we introduce local-currency debt. Both long-term debt and local-currency debt carry more risk-sharing than short-term foreign-currency debt, and therefore share some similarities with equity financing. But each is also different from equity financing in some ways.

\subsection{Passive Equity Versus FDI}

In our baseline model, we do not differentiate between passive equity and foreign direct investment. The key difference between them lies in the control right. Presumably, if foreign investors possess control right, it would reduce informational asymmetry between the foreign investors and the domestic CEO and consequently make it more difficult for the domestic CEO to cheat foreign investors. However, foreign investors would need to set aside additional resources in order to conduct FDI and not all investors wish to do that. For example, it may be expensive for an international hedge fund or mutual fund to hire competent managers to be stationed in the host country. This might create a trade-off for FDI investment versus passive equity investment as in Goldstein and Razin (2006). In this section, we aim to incorporate such a tradeoff into our model.

To guide our model development, we look at the relationship between FDI investment and institutional quality in the data. Figure 7 reports the average relationship during 1996- 
Figure 7 FDI SHARE (IN EQUITY) AND INSTITUTIONAL QUALITY:

\section{RAW AND BIN SCATTER PLOTS}
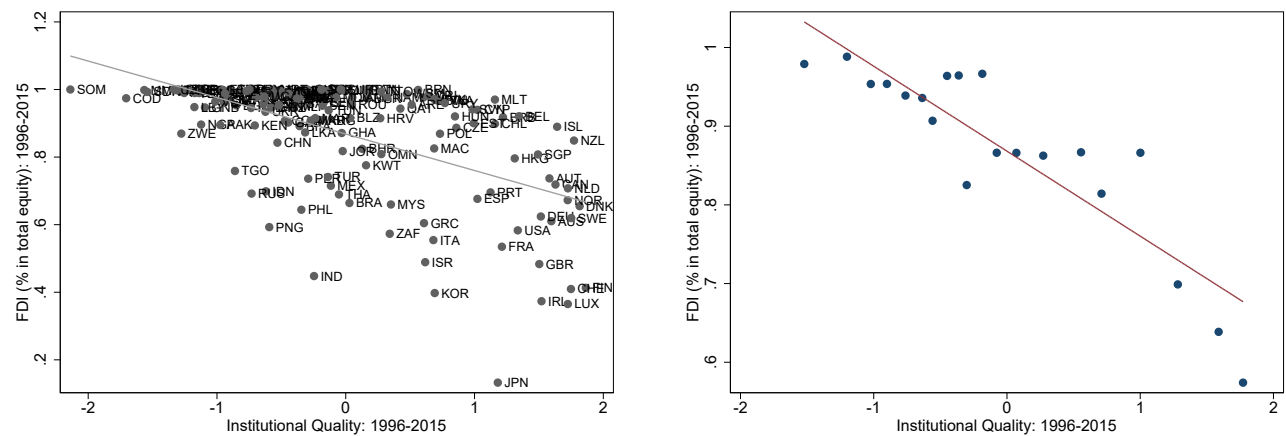

Note. This first figure shows the relationship between FDI share (\% in total equity liability) and domestic institutional quality during 1996-2015. Each dot represents a country's average FDI share and average quality measure during this period. The second figure is a bin scatter plot version of the first figure.

2015. Clearly, one can see that FDI shares in total equity liability falls with institutional quality. This can be interpreted as evidence that asymmetric information and moral hazard by domestic agents are relieved by improvement in institutional quality. Therefore, the benefit from obtaining a control right through FDI becomes relatively less important.

To capture this idea, we assume that foreign direct investment requires a fixed cost $c_{i} y_{1}$ with $c_{i} \in[0,1]$ for an investor $i$. Depending on the cost parameter $c_{i}$, investors will decide on either passive equity investment or FDI so as to maximize the expected payoff. Denote the total units of equity (passive equity and FDI) as $s \in[0,1]$, of which the share of passive equity is denoted as $\pi \in[0,1]$. The domestic household decides to sell passive equity at price $p_{e}$ and FDI at price $p_{f}$. The bond can be sold at price $p_{d}$ as before. In this environment, the period-1 budget constraint is given by

$$
C_{T 1}=p_{d} d+s\left[p_{e} \pi+p_{f}(1-\pi)\right]
$$

We need to work out $\left\{p_{d}, p_{e}, p_{f}\right\}$ in equilibrium. Similar to our benchmark model, we will assume that the bankruptcy cost is high enough such that domestic CEO never cheats on debt investors, which implies $p_{d}=\frac{1}{1+r}$. For the prices of FDI and passive equity, we will impose equilibrium conditions. Define the marginal international investor with $\bar{c}$ as the 
one who is indifferent between FDI and passive equity investment. By definition,

$$
(1-\theta) y_{1}-p_{e}=y_{1}-\left(p_{f}+\bar{c} y_{1}\right)
$$

Therefore,

$$
\bar{c}=\theta+\frac{p_{e}-p_{f}}{y_{1}}
$$

From this condition, one can see that investors with $c_{i}>\bar{c}$ choose passive equity over FDI while the rest chooses FDI over equity. Therefore, the share of FDI investors is given by $\bar{c}$. In equilibrium, $\pi=1-\bar{c}$. Moreover, the prices of FDI and equity should make investors to earn zero profit ex ante. That is

$$
0=\int_{\bar{c}}^{1}\left[(1-\theta) y_{1}-p_{e}\right] d c_{i}+\int_{0}^{\bar{c}}\left(y_{1}-c_{i} y_{1}-p_{f}\right) d c_{i}
$$

Given this equilibrium condition, one can show that $p_{e}=p_{f}$. We can prove this by contradiction. If $p_{e}>p_{f}$, the domestic agents will prefer passive equity (see equation (6)), i.e. $\pi=1$ and $\bar{c}=0$. However, when $p_{e}>p_{f}$ and $\bar{c}>\theta \geq 0$. By the same argument, one can show that $p_{e}<p_{f}$ cannot hold in equilibrium. With the zero-profit condition, one can solve the price of equity given by $p_{e}=p_{f}=\frac{1+(1-\theta)^{2}}{2} y_{1}$.

With this simple modification, this new model preserves the key insight from the baseline model while matching data pattern on the FDI share in total equity liability. To see this, the share of FDI in total equity financing is given by $\bar{c}=\theta$. Therefore, the FDI share in total equity falls with a lower value of $\theta$, i.e. a better institutional quality. Moreover, there is a linear transformation between this new model and our baseline model. One can redefine $\theta^{\prime} \equiv \frac{\theta(2-\theta)}{2}$ and then $p_{e}=\left(1-\theta^{\prime}\right) y_{1}$. In such a scenario, all the analysis in the baseline model carries over to the new framework.

\subsection{Long-term Debt}

Long-term debt could also provide better risk-sharing than short-term debt. For example, one can introduce a long-term debt $D$ with a promised return $(1+r)^{2}$ at period 3 in addition to the short-term debt $d$ at period 1 . If there were no additional cost associated with 
the long-term debt, the economy would strictly prefer long-term debt to short-term debt because long-term debt avoids the binding constraint in the second period. To be more realistic, we assume that institutional quality also affects the issuance of long-term debt as in Wei and Zhou (2018). Specifically, long-term debt investors face a "dilution risk" in countries with a weak institutional environment - the CEO in the capital recipient country may issue additional short term debt in period 2 before the long-term debt matures in period 3. As the additional short-term debt dilutes the expected payoff to long-term debt, the long-term debt investors may ask the firm not to issue additional short-term debt or make the long-term debt senior to any new short-term debt. However, the ability to enforce such covenant depends on the capital recipient country's institutional quality.

The budget constraints in an economy with long-term debt can be written as

$$
\begin{aligned}
& C_{T 1}=\frac{d}{1+r}+(1-\theta) \frac{D}{(1+r)^{2}} \\
& p C_{N 2}+C_{T 2}=y_{2}-d+p y_{N 2}+\frac{d^{\prime}}{1+r} \\
& C_{T 3}=y_{3}-d^{\prime}-D
\end{aligned}
$$

The long-term bond provides better risk-sharing than the short-term bond since it avoids the costly binding financial constraint in the second period. However, the long-term bond holder is vulnerable to an expropriation (dilution) risk. The equilibrium strikes a balance between these two. Due to the same pecuniary externality as in the baseline model, the economy displays an over-borrowing problem that applies only to the short-term bond. The social planner uses capital controls to correct the problem. The following proposition summarizes the key results.

Proposition 8. When the economy can issue both long-term and short-term debt, the competitive equilibrium features a combination of both whose ratio depends on the institutional quality $\theta$. Specifically, there exists two thresholds $\{\underline{\theta}, \bar{\theta}\}$ such that a combination of shortterm and long-term debt exists when $\theta \in(\underline{\theta}, \bar{\theta})$. When the institutional quality is high enough, i.e. $\theta<\underline{\theta}$, the economy uses only long-term debt. On the other extreme, when the institutional quality is sufficiently low, i.e. $\theta>\bar{\theta}$, there is only short-term debt in equilib- 
rium. In this economy, pecuniary externality only affects the short-term debt. The social planner would impose a tax on short-term borrowing to correct the overborrowing problem.

Proof. The proof is given in Appendix F.6.

As in our benchmark model with equity and short-term debt, the combination of longterm and short-term debt depends ultimately on the degree of institutional quality. In fact, in our setup, the long-term debt is better than equity since its issuance is not affected by the pecuniary externality associated with short-term debt. However, this is due to the assumption that the collateral constraint only shows up in the second period and the long-term debt matures in the last period.

In general, the long-term debt can also be affected by a pecuniary externality if a collateral constraint exists in the period when the long-term debt matures. In that case, equity financing likely still dominates the long-term debt other things equal since it provides more risk-sharing. In other words, in a model with long-term debt, short-term debt, and equity, the equilibrium proportions of the three securities depend on how institutional quality affects their respective prices.

\subsection{Local-Currency Debt}

We assume that the economy can issue both dollar-denominated debt $d$ and local-currency debt $l$ in period $1 .{ }^{13}$ As in the benchmark economy, the dollar-denominated debt has a promised return of world interest rate $r$ and is thus priced at $\frac{1}{1+r}$. The return on localcurrency debt is expressed in terms of units of tradable good and denoted by $\rho$. Since international investors are risk-neutral, a no-arbitrage condition requires the following

$$
E[\rho]=1+r
$$

\footnotetext{
${ }^{13}$ While we could introduce local-currency debt in period 2, it would add no new insight. Without uncertainty in period 3, the local-currency debt and dollar-denominated debt would have been perfect substitutes (see Korinek (2009)).
} 
Since return $\rho$ depends on the realized real exchange rate $p$ in period 2, it implies that

$$
\rho=\frac{p}{E[p]}(1+r)
$$

If the local-currency debt $l$ could be issued without additional cost, the country would prefer this due to its better risk-sharing property. It has been observed that developing countries are usually not able to issue local-currency debt to international investors - a phenomenon labeled as the "original sin" by Eichengreen and Hausmann (1999). A possible explanation is an inability of these countries to credibly commit not to use inflation to expropriate the holders of local-currency debt in economic downturns (see a formulation of the idea by Engel and Park (2018)). It is reasonable to assume that those countries with poorer institutional quality are less able to commit to price stability in their monetary policy. A hallmark for poor public institutions is excessive discretionary power by government officials and relatively few constraints on their power. These same features also likely to prevent their central banks from making credible commitments in the conduct of monetary policy. As a consequence, their local-currency debt will be discounted more by international investors. With a slight abuse of notations, we capture the extent of the discount by $\theta$. Given this structure, the budget constraints in periods 1 and 2 become

$$
\begin{aligned}
& C_{T 1}=\frac{d}{1+r}+l(1-\theta) \\
& p C_{N 2}+C_{T 2}=y_{2}+p y_{N 2}-d-\rho l+\frac{d^{\prime}}{1+r}
\end{aligned}
$$

The equilibrium configuration of debt can be summarized by the following proposition.

Proposition 9. When the economy can issue both dollar-denominated and local-currency debt, their equilibrium combination depends on the value of institutional quality $\theta$ relative to two threshold levels, $\{\underline{\theta}, \bar{\theta}\}$. When the institutional quality is good enough, i.e. $\theta<\underline{\theta}$, there is only local-currency debt. When the institutional quality is poor enough, i.e. $\theta>\bar{\theta}$, there is only dollar debt. When $\theta \in(\underline{\theta}, \bar{\theta})$, there is a mixture of both types of debt.

Proof. The proof is given in Appendix F.7. 


\section{Social Planner with Commitment}

A pecuniary externality in this economy calls for policy intervention. In particular, the social planner internalizes the general equilibrium effect through real exchange rate $p$. Note that the policy intervention itself also faces a commitment issue. Since the payoff for the local-currency debt $\rho$ is given by $\frac{p}{E[p]}(1+r)$, if the planner could commit in Period- 1 to a consumption profile $C_{T 2}$, it can change the payoff structure across states in period 2 , which ultimately affects period-1 consumption. However, in period 2, the planner has an incentive to deviate from her original plan when a particular state is actually materialized. We assume that the social planner can commit. Her problem is given below.

$$
\begin{array}{cl}
V^{C}(\theta)=\max _{d, l, C_{T 1}, C_{T 2}, d^{\prime}, C_{T 3}} & \omega_{T} \log C_{T 1}+\beta E\left[\omega_{T} \log C_{T 2}+\omega_{N} \log y_{N 2}+\beta \omega_{T} \log C_{T 3}\right] \\
\text { s.t. } & C_{T 1}=\frac{d}{1+r}+(1-\theta) l \\
& C_{T 2}=y_{2}-d+\frac{d^{\prime}}{1+r}-\rho\left(C_{T 2}, E\left[C_{T 2}\right]\right) l \\
& \frac{d^{\prime}}{1+r} \leq \phi\left(y_{2}+\frac{\omega_{N}}{\omega_{T}} C_{T 2}\right) \\
& C_{T 3}=y_{3}-d^{\prime}
\end{array}
$$

Proposition 10. A social planner with commitment chooses a different allocation from the private agents. To correct the inefficiency, three capital control taxes are needed on period-1 dollar debt and local-currency debt $\left\{\tau_{d}, \tau_{l}\right\}$ and on period-2 dollar debt $\tau_{d^{\prime}}$.

$$
\begin{aligned}
& \tau_{d}=\beta(1+r) E_{1}\left[\frac{\phi \mu^{C} \frac{\omega_{N}}{\omega_{T}}-\frac{\omega_{T}}{C_{T 2}} l\left(\frac{\partial \rho}{\partial C_{T 2}}+f\left(y_{2}\right) \frac{\partial \rho}{\partial E\left[C_{T 2}\right]}\right)}{1+l\left(\frac{\partial \rho}{\partial C_{T 2}}+f\left(y_{2}\right) \frac{\partial \rho}{\partial E\left[C_{T 2}\right]}\right)}\right] /\left(\frac{\omega_{T}}{C_{T 1}}\right) \\
& \tau_{l}=\beta E_{1}\left[\frac{\phi \mu^{C} \frac{\omega_{N}}{\omega_{T}}-\frac{\omega_{T}}{C_{T 2}} l\left(\frac{\partial \rho}{\partial C_{T 2}}+f\left(y_{2}\right) \frac{\partial \rho}{\partial E\left[C_{T 2}\right]}\right)}{1+l\left(\frac{\partial \rho}{\partial C_{T 2}}+f\left(y_{2}\right) \frac{\partial \rho}{\partial E\left[C_{T 2}\right]}\right)} \rho\right] /\left(\frac{\omega_{T}}{C_{T 1}}\right) /(1-\theta) \\
& \tau_{d^{\prime}}=\frac{l\left(\frac{\partial \rho}{\partial C_{T 2}}+f\left(y_{2}\right) \frac{\partial \rho}{\partial E\left[C_{T 2}\right]}\right)}{1+l\left(\frac{\partial \rho}{\partial C_{T 2}}+f\left(y_{2}\right) \frac{\partial \rho}{\partial E\left[C_{T 2}\right]}\right)}
\end{aligned}
$$


Proof. Proof is given in Appendix F.7

Since there are two types of inefficiencies in the competitive equilibrium, it can produce either over-borrowing or under-borrowing relative to the social planner's solution. The exact parameter values matter. Nevertheless, capital controls can be put in place to implement the optimal allocation under commitment.

\section{A Government's Solution}

A government that sees the market failure in the decentralized equilibrium may wish to intervene. However, a government's ability to commit and hence its ability to replicate the social planner's solution cannot be taken for granted. We consider the case of a government whose ability to commit depends on the institutional quality. Poorer institutional quality is assumed to imply a weaker commitment ability. To capture such a distortion, we introduce a welfare loss related to $\theta, \Psi(\theta)$, and define a government's problem as follows.

$$
V^{B}(\theta)=V^{C}(\theta)-\Psi(\theta)
$$

The desirability of the capital controls can be ascertained by comparing the welfare from the bureaucratic solution $V^{B}(\theta)$ with the welfare in the competitive equilibrium. Only when the former is larger than the latter would it be desirable to impose capital controls. Otherwise, the welfare loss from weak commitment $\Psi(\theta)$ could overwhelm the gains from capital controls. In short, the institutional quality matters for the type of capital controls - not only through its impact on the price of local-currency debt (as in our benchmark economy) but also through its impact on the commitment ability of the government.

To summarize, local-currency debt provides better risk-sharing than dollar debt. Similar to equity issuance, its cost depends on the quality of institutions. Therefore, the equilibrium composition of the securities depends on the effect of institutional quality on their costs. A difference between local-currency debt and equity is that the former involves a commitment problem, which depends on the institutional quality. In general, local-currency debt does not dominate equity financing since correcting the inefficiency in local-currency debt requires the government to have a strong commitment power. 


\section{Conclusion}

This paper provides a tractable framework to study the role of institutional quality in determining both a country's external capital structure and its optimal capital controls. We articulate two forms of asymmetries between equity and debt, and between international investors and emerging market economies. The first asymmetry is that, from the viewpoint of a capital recipient country, equity financing provides more sharing of the real-side risks than debt financing. This means that the capital recipient country prefers equity financing to debt financing, other things equal. The second asymmetry is that, from the viewpoint of international investors, equity financing is more vulnerable to expropriation risks in a capital recipient country than debt financing. This means that international investors are more willing to offer debt financing than equity financing to a country with a high level of expropriation risk. The equilibrium composition of capital inflows and the equilibrium likelihood of an economic crisis are both determined by the capital recipient country's institutional quality (among other factors). As a consequence, a country's need to impose capital controls to correct the inefficiency depends on the quality of its institutions.

Our story can be compared with an alternative narrative that focuses on cross-country differences in financial development. While either a relaxation of collateral constraint or an improvement in the institutional quality can reduce the probability of a crisis, there are important differences. First, while a more relaxed borrowing constraint tends to reduce the ratio of equity to debt financing, better institutions would produce an opposite change. Second, while a more relaxed borrowing constraint tends to lead to a higher capital control tax, better institutions would reduce capital controls.

Our paper has implications for corrective measures. The best action to correct pecuniary externality is reforms that raise institutional quality. Better quality increases both financial stability and economic efficiency simultaneously. The optimal capital controls are a second-best policy to be used when institutional reform is not attainable. The case for capital controls weakens endogenously with an improvement in the quality of institutions.

To the best of our knowledge, this is the first paper to analyze optimal capital controls in a framework with an endogenous capital structure. Besides equity financing, we have considered several extensions by allowing for other securities that also have (partial) risksharing properties, such as local-currency debt and long-maturity debt. But more can be 
done in future research. There are a number of directions to extend our work. For example, it could be interesting to embed our setup in a DSGE framework as in Bianchi (2011) and Jeanne and Korinek (2018). In addition, our formulation may be used to study pro-cyclical leverage ratios and the corresponding optimal policies.

\section{References}

Adrian, T. AND H. S. SHIN (2014): "Procyclical Leverage and Value-at-risk," Review of Financial Studies, 27, 373-403.

ARCE, F., J. Bengui, And J. BiAnchi (2019): "A Macroprudential Theory of Foreign Reserve Accumulation,” NBER Working Paper No. 26236.

Benigno, G., H. Chen, C. Otrok, A. Rebucci, And E. R. Young (2013): "Financial Crises and Macro-prudential Policies," Journal of International Economics, 89, 453-470.

(2016): "Optimal Capital Controls and Real Exchange Rate Policies: A Pecuniary Externality Perspective,” Journal of Monetary Economics, 84, 147-165.

BIANCHI, J. (2011): "Overborrowing and Systemic Externalities in the Business Cycle," American Economic Review, 101, 3400-3426.

Bianchi, J. And E. G. Mendoza (2018): “Optimal Time-consistent Macroprudential Policy," Journal of Political Economy, 126, 588-634.

Calvo, G. A., A. IzQuierdo, And E. Talvi (2006): "Sudden Stops and Phoenix Miracles in Emerging Markets," American Economic Review, 96, 405-410.

Chamon, M. And M. Garcia (2016): “Capital Controls in Brazil: Effective?” Journal of International Money and Finance, 61, 163-187.

Coeurdacier, N. And H. Rey (2013): "Home Bias in Open Economy Financial Macroeconomics," Journal of Economic Literature, 51, 63-115.

DÁvila, E. AND A. KorineK (2018): "Pecuniary Externalities in Economies with Financial Frictions," Review of Economic Studies, 85, 352-395.

EICHENGREen, B. AND R. HAUSMANN (1999): "Exchange Rates and Financial Fragility," NBER Working Paper No. 7418. 
Engel, C. AND J. PARK (2018): "Debauchery and Original Sin: The Currency Composition of Sovereign Debt," NBER Working Paper No. 24671.

FARHI, E. AND I. WERning (2014): "Dilemma not Trilemma? Capital Controls and Exchange Rates with Volatile Capital Flows," IMF Economic Review, 62, 569-605.

- (2016): "A Theory of Macroprudential Policies in the Presence of Nominal Rigidities," Econometrica, 84, 1645-1704.

Fernández, A., M. W. Klein, A. Rebucci, M. Schindler, And M. URibe (2016): "Capital Control Measures: A New Dataset," IMF Economic Review, 64, 548-574.

Forbes, K., M. Fratzscher, T. Kostka, And R. Straub (2016): "Bubble Thy Neighbor: Portfolio Effects and Externalities from Capital Controls," Journal of International Economics, 99, 85-104.

Forbes, K. J. And F. E. WARnock (2012): "Capital Flow Waves: Surges, Stops, Flight, and Retrenchment," Journal of International Economics, 88, 235-251.

Frankel, J. A. And A. K. Rose (1996): “Currency Crashes in Emerging Markets: An Empirical Treatment," Journal of International Economics, 41, 351-366.

Geanakoplos, J. And H. M. Polemarchakis (1986): "Existence, Regularity, and Constrained Suboptimality of Competitive Allocations When the Asset Market Is Incomplete," in Essays in Honor of Kenneth Arrow, ed. by R. S. W. Heller and D. Starrett, Cambridge University Press, vol. 3, chap. 3, 65-95.

Goldberg, P. K. And G. Maggi (1999): "Protection for Sale: An Empirical Investigation," American Economic Review, 89, 1135-1155.

Goldstein, I. AND A. RAZIN (2006): “An Information-based Trade Off between Foreign Direct Investment and Foreign Portfolio Investment,' Journal of International Economics, 70, 271-295.

Greenwald, B. C. And J. E. Stiglitz (1986): "Externalities in Economies with Imperfect Information and Incomplete Markets," Quarterly Journal of Economics, 101, 229-264.

Grossman, G. M. And E. Helpman (1994): "Protection for Sale," American Economic Review, 833-850.

Holmstrom, B. (2015): "Understanding the Role of Debt in the Financial System," BIS Working Paper No. 479. 
JeAnne, O. And A. KorineK (2010): "Excessive Volatility in Capital Flows: A Pigouvian Taxation Approach," American Economic Review, 403-407.

- (2018): "Managing Credit Booms and Busts: A Pigouvian Taxation Approach," Journal of Monetary Economics.

- (2020): "Macroprudential Regulation versus Mopping up After the Crash," Review of Economic Studies, 87, 1470-1497.

JiAO, Y. AND S.-J. WEI (2017): "Intrinsic Openness and Endogenous Institutional Quality," NBER Working Paper No. 24052.

KorineK, A. (2009): "Insurance Properties of Local and Foreign Currency Bonds in Small Open Economies," Manuscript.

- (2018): "Regulating Capital Flows to Emerging Markets: An Externality View," Journal of International Economics, 111, 61-80.

KorineK, A. And E. G. Mendoza (2014): "From Sudden Stops to Fisherian Deflation: Quantitative Theory and Policy," Annual Review of Economics, 6, 299-332.

KorineK, A. And A. Simsek (2016): "Liquidity Trap and Excessive Leverage," American Economic Review, 106, 699-738.

Kose, M. A., E. Prasad, K. Rogoff, And S.-J. Wei (2010): "Financial Globalization and Economic Policies," in Handbook of Development Economics, Elsevier, vol. 5, 4283-4359.

Laeven, L. And F. VAlencia (2013): "Systemic Banking Crises Database," IMF Economic Review, 61, 225-270.

Lane, P. R. And G. M. Milesi-Ferretti (2007): “The External Wealth of Nations Mark II: Revised and Extended Estimates of Foreign Assets and Liabilities, 1970-2004," Journal of International Economics, 73, 223-250.

Lorenzoni, G. (2008): "Inefficient Credit Booms," Review of Economic Studies, 75, 809-833.

MA, C. (2020): "Financial Stability, Growth and Macroprudential Policy," Journal of International Economics, 122, 103259.

Mendoza, E. G. (2010): "Sudden Stops, Financial Crises, and Leverage," American Economic Review, 100, 1941-1966. 
Modigliani, F. And E. Perotti (2000): "Security Markets versus Bank Finance: Legal Enforcement and Investors' Protection," International Review of Finance, 1, 81-96.

Ostry, M. J. D., M. A. R. Ghosh, M. K. F. Habermeier, M. M. Chamon, M. S. QuREshi, AND D. B. ReInHARDT (2010): "Capital Inflows: The Role of Controls," IMF Staff Position Note.

SChMitT-Grohé, S. AND M. URIBE (2016): "Downward Nominal Wage Rigidity, Currency Pegs, and Involuntary Unemployment," Journal of Political Economy, 124, 14661514.

(forthcoming): "Multiple Equilibria in Open Economies with Collateral Constraints," Review of Economic Studies.

TONG, H. AND S.-J. WEI (2010): “The Composition Matters: Capital Inflows and Liquidity Crunch During a Global Economic Crisis," Review of Financial Studies, 24, 20232052.

WEI, S.-J. (2000): "Local Corruption and Global Capital Flows," Brookings Papers on Economic Activity, 31, 303-354.

WeI, S.-J. AND J. ZHOU (2018): "Quality of Public Governance and the Capital Structure of Nations and Firms," NBER Working Paper No. 24184. 


\section{A Country List (online only)}

The sample includes the following 159 economies:

\begin{tabular}{|c|c|c|c|c|c|c|c|}
\hline Albania & Bulgaria & Denmark & Guinea-Bissau & Kyrgyz Republic & Morocco & Qatar & Sao Tome \&Principe \\
\hline Algeria & Burkina Faso & Djibouti & Guyana & Lao People's Dem.Rep & Mozambique & Romania & Tanzania \\
\hline Angola & Burundi & Dominican Republic & Haiti & Latvia & Myanmar & Russia & Thailand \\
\hline Argentina & Cambodia & Ecuador & Honduras & Lebanon & Namibia & Rwanda & Togo \\
\hline Armenia & Cameroon & Egypt & Hong Kong & Lesotho & Nepal & Samoa & Trinidad and Tobago \\
\hline Australia & Canada & El Salvador & Hungary & Liberia & Netherlands & Saudi Arabia & Tunisia \\
\hline Austria & Central African Rep. & Eritrea & Iceland & Libya & New Zealand & Senegal & Turkey \\
\hline Azerbaijan & Chad & Estonia & India & Lithuania & Nicaragua & Sierra Leone & Turkmenistan \\
\hline Bahrain & Chile & Ethiopia & Indonesia & Luxembourg & Niger & Singapore & Uganda \\
\hline Bangladesh & China,P.R.: Mainland & Fiji & Iran, Islamic Republic of & Macedonia & Nigeria & Slovak Republic & Ukraine \\
\hline Barbados & China,P.R.:Macao & Finland & Ireland & Madagascar & Norway & Slovenia & United Arab Emirates \\
\hline Belarus & Colombia & France & Israel & Malawi & Oman & Somalia & United Kingdom \\
\hline Belgium & Comoros & Gabon & Italy & Malaysia & Pakistan & South Africa & United States \\
\hline Belize & Congo, Dem. Rep. of & Gambia, The & Jamaica & Maldives & Panama & Spain & Uruguay \\
\hline Benin & Congo, Republic of & Georgia & Japan & Mali & Papua New Guinea & Sri Lanka & Uzbekistan \\
\hline Bhutan & Costa Rica & Germany & Jordan & Malta & Paraguay & Sudan & Venezuela, Rep. Bol. \\
\hline Bolivia & Croatia & Ghana & Kazakhstan & Mauritania & Peru & Suriname & Vietnam \\
\hline Botswana & Cyprus & Greece & Kenya & Mexico & Philippines & Swaziland & Zambia \\
\hline Brazil & Czech Republic & Guatemala & Korea & Moldova & Poland & Sweden & Zimbabwe \\
\hline Brunei Darussalam & Cote d'Ivoire & Guinea & Kuwait & Mongolia & Portugal & Switzerland & \\
\hline
\end{tabular}




\section{B Data Source (online only)}

We combine five data sources: the External Wealth of Nations (EWN) data set from Lane and Milesi-Ferretti (2007), the Worldwide Governance Indicators (WGI) from the World Bank Institute, sudden stop episodes from Korinek and Mendoza (2014), banking crises from Laeven and Valencia (2013), and capital controls from Fernández et al. (2016).

External Capital Structure The EWN data set provides detailed information on the external liability structure for most countries during 1970-2015. To construct the share of equity in total liability, we use the sum of portfolio equity liabilities (stock) and FDI liability (stock) divided by total liabilities.

Institutional Quality The WGI database provides six measures of government institutional quality for most World Bank member countries from 1996-2017. ${ }^{14}$ They are: Control of Corruption (CC), Government Effectiveness (GE), Political Stability and Absence of Violence/Terrorism (PS), Rule of Law (PL), Regulatory Quality (RQ) and Voice and Accountability (VA). Each index is constructed in units of a standard normal distribution, i.e. ranging from -2.5 to 2.5 , where a higher value means a higher quality institution. All six measures are highly correlated with each other as shown in Table C.2. Furthermore, the cross country ranking is stable over time. Following Wei and Zhou (2018), we use the simple average of the six measures as our proxy for institutional quality.

Probability of Crises We use two measures. The first is an indicator of banking crises proposed by Laeven and Valencia (2013). The second is an indicator of the sudden stop episodes identified by Korinek and Mendoza (2014), who have extended Calvo et al. (2006) by examining episodes with a capital flow reversal and a sharp increase in the aggregate EMBI spread for emerging economies or VIX for advanced economies.

Capital Controls Measure We use capital controls data constructed by Fernández et al. (2016) that is based on the IMF's Annual Report on Exchange Arrangements and Exchange Restrictions (AREAER). The AREAER contains descriptions and summaries of de jure restrictions in each of the IMF member countries. ${ }^{15}$ Fernández et al. (2016) translate the narrative in the AREAER database into a 0/1 qualitative indicator denoting the absence (0) or presence (1) of controls. To proxy for restrictions on foreign purchases by non-residents, we use the measure for "purchase locally by non-residents."

\footnotetext{
${ }^{14}$ For three years with missing data, i.e. 1997, 1999 and 2001, we linearly interpolate the missing data.

${ }^{15}$ There are 10 asset categories in the data set, including equity (EQ), bonds with an original maturity of more than one year (BO), money market instruments (MM), collective investment securities such as mutual funds and investment trusts (CI), derivatives (DE), commercial credits (CC), financial credits (FC), guarantees, sureties and financial back-up facilities (GS), direct investment (DI), and real estate transactions (RE).
} 
Our sample consists of 159 economies (Appendix A) during 1996-2015. The summary statistics are in Appendix Table C.1. The variable construction is given below:

Equity (\% of total liabilities) is constructed as the ratio of the sum of portfolio equity liabilities and FDI liabilities over total liabilities, based on Lane and Milesi-Ferretti (2007).

Institutional Quality is the average of the six Worldwide Governance Indicators from the World Bank Institute.

Sudden Stop Indicator is from Korinek and Mendoza (2014).

Systemic Banking Crises Indicator is from Laeven and Valencia (2013).

GDP per capita (constant 2010 US\$), Domestic Private Credit (in \% of GDP), and Trade/GDP are from the World Development Indicators (WDI).

Capital Control measures are from Fernández et al. (2016).

\section{Appendix Tables (online only)}

Table C.1 Summary STATistics

\begin{tabular}{lccccc}
\hline Variable & Obs & Mean & Std.Dev. & Min & Max \\
\hline Equity (\% of total liability) & 3180 & 38.57 & 20.55 & 0 & 95.22 \\
Institutional Quality & 3180 & -0.05 & 0.92 & -2.45 & 1.97 \\
log GDP per capita & 3107 & 8.39 & 1.58 & 4.81 & 11.61 \\
Private Credit & 2980 & 47.88 & 44.91 & 0.19 & 312.2 \\
Trade & 3038 & 87.64 & 53.38 & 0.31 & 455.3 \\
\hline
\end{tabular}

\section{Aggregate Demand Externality (online only)}

This appendix uses a three-period model to discuss how the insight on an endogenous composition of capital flows affects the aggregate demand externality emphasized by SchmittGrohé and Uribe (2016). The aggregate demand externality emerges from a combination of a fixed exchange rate regime and a downward rigidity with nominal wage. 
Table C.2 PAIRWISE CORRELATION FOR INSTITUTIONAL QUALITY

\begin{tabular}{lllllll}
\hline \hline & CC & GE & PS & RL & RQ & VA \\
\hline Control of Corruption (CC) & 1.00 & & & & & \\
Government Effectiveness (GE) & $0.94^{*}$ & 1.00 & & & & \\
Political Stability and Absence of Violence/Terrorism (PS) & $0.75^{*}$ & $0.74^{*}$ & 1.00 & & & \\
Rule of Law (PL) & $0.88^{*}$ & $0.94^{*}$ & $0.72^{*}$ & 1.00 & & \\
Regulatory Quality (RQ) & $0.95^{*}$ & $0.96^{*}$ & $0.79^{*}$ & $0.93^{*}$ & 1.00 & \\
Voice and Accountability (VA) & $0.78^{*}$ & $0.79^{*}$ & $0.66^{*}$ & $0.82^{*}$ & $0.82^{*}$ & 1.00 \\
\hline \hline
\end{tabular}

Note. The * shows significance at the 0.01 level.

Table C.3 PARAMETER VALUES FOR NUMERICAL EXAMPLE

\begin{tabular}{ccccccccc}
\hline$\omega_{T}$ & $\omega_{N}=1-\omega_{T}$ & $r$ & $\beta=(1+r)^{-1}$ & $\varepsilon$ & $\phi$ & $y_{N 2}$ & $\bar{y}_{2}$ & $y_{3}$ \\
\hline 0.3 & 0.7 & $5 \%$ & 0.95 & 0.05 & 0.3 & 1 & 1 & 1 \\
\hline
\end{tabular}

The economy features two types of goods, tradable and non-tradable. For simplicity, non-tradable consumption appears only in the first two periods. The preference of a representative agent is given by

$$
E\left[\log C_{1}+\beta \log C_{2}+\beta^{2} \omega_{T} \log C_{T 3}\right], \text { with } C_{t}=C_{T t}^{\omega_{T}} C_{N t}^{\omega_{N}}, \text { for } t=1,2
$$

where $\beta$ is the discount rate, $\omega_{T}\left(\omega_{N}=1-\omega_{T}\right)$ equals to the share of tradable (non-tradable) consumption in the total spending, and $C_{T t}\left(C_{N t}\right)$ is the tradable consumption.

Income Stream As in the benchmark model, the tradable income stream is assumed to be exogenous and given by $\left\{y_{T 1}=0, y_{T 2}, y_{T 3}\right\}$. The only source of risk is from $y_{T 2}$ which is uniformly distributed from $U[\underline{y}, \bar{y}]$.

Non-tradable sector The non-tradable income is endogenous, given by $y_{N t}=z_{t} h_{t}^{\alpha}$, where $z_{t}$ is the level of TFP in the non-tradable sector, $h_{t}$ is the labor demand and $\alpha \in(0,1)$ is a parameter in the production. A non-tradable sector firm chooses labor $h_{t}$ for a given (nominal) wage $W_{t}$ and (nominal) non-tradable price $P_{N t}$ to maximize its profit.

Following Schmitt-Grohé and Uribe (2016), we assume that $W_{t} \geq \gamma W_{t-1}$, with $\gamma \geq 0$ denoting the degree of nominal rigidity. As the past wage puts a floor on feasible wage adjustment, a representative firm's optimization problem in periods 1 and 2 is given by

$$
\Pi_{t}=\max _{h_{t}} P_{N t} y_{N t}-W_{t} h_{t}, \text { s.t. } W_{t} \geq \gamma W_{t-1}
$$


The optimality condition implies that

$$
\alpha P_{N t} z_{t} h_{t}^{\alpha-1}=W_{t}
$$

The representative household is assumed to supply labor inelastically. The total labor supply is bounded by the labor endowment $\bar{h}$, i.e. $h_{t} \leq \bar{h}$. As long as $W_{t} \geq \gamma W_{t-1}$ does not bind, the economy features full employment in the non-tradable sector and $h_{t}=\bar{h}$. Otherwise, there is involuntary unemployment. This implies

$$
h_{t}^{*}=\min \left\{\bar{h},\left(\frac{\alpha P_{N t} z_{t}}{\gamma W_{t-1}}\right)^{\frac{1}{1-\alpha}}\right\}
$$

and

$$
\left(W_{t}-\gamma W_{t-1}\right)\left(h_{t}^{*}-\bar{h}\right)=0
$$

The representative domestic agent can issue one-period debt $d$ with a promised return of $1+r$, or sell $s$ shares of equity claim on tradable income at price $p_{e}$ at period 1 , with $p_{e}=(1-\theta) y_{1}$ and $y_{1} \equiv \frac{\frac{y+\bar{y}}{2}+\frac{y_{T 3}}{1+r}}{1+r}$. In period 2 , he can issue debt $d^{\prime}$ to smooth consumption.

The budget constraints for the domestic agent in the three periods are given by

$$
\begin{aligned}
& P_{N 1} C_{N 1}+P_{T 1} C_{T 1}=W_{1} h_{1}+\Pi_{1}+\left[s p_{e}+\frac{d}{1+r}\right] \mathcal{E}_{1}, \\
& P_{N 2} C_{N 2}+P_{T 2} C_{T 2}=W_{2} h_{2}+\Pi_{2}+P_{T 2}(1-s) y_{T 2}-\mathcal{E}_{2} d+\mathcal{E}_{2} \frac{d^{\prime}}{1+r}, \\
& P_{T 3} C_{T 3}=P_{T 3}(1-s) y_{T 3}-\mathcal{E}_{3} d^{\prime}
\end{aligned}
$$

where $\mathcal{E}_{t}$ denotes the nominal exchange rate and $P_{T t}$ is the nominal price of tradable good. For tradable goods, we assume that the law of one price holds:

$$
P_{T t}=\mathcal{E}_{t} P_{T t}^{*}
$$

Normalizing $P_{T t}^{*}=1$, we obtain the following

$$
P_{T t}=\mathcal{E}_{t}
$$

Assume that $W_{0}$ is low enough such that the wage constraint does not bind in period 1 . The constraint may bind in period 2 if there is an unfavorable realization of the tradable income in that period. We focus on the case of a fixed exchange rate as in Schmitt-Grohé 
and Uribe (2016), i.e. $\mathcal{E}_{1}=\mathcal{E}_{2}=\mathcal{E}_{3}$. The problem can be rewritten as

$$
\begin{aligned}
& W=\max _{C_{T 1}, C_{N 1}, s, d} \omega_{T} \log C_{T 1}+\omega_{N} \log C_{N 1}+\beta E_{1}\left[V\left(w_{1}, s, d\right)\right], \\
& \text { s.t. } \quad p_{N 1} C_{N 1}+C_{T 1}=w_{1} \bar{h}+\pi_{1}+\left[s p_{e}+\frac{d}{1+r}\right]
\end{aligned}
$$

where the lower case variable $x_{t}$ such as $p_{N t}, w_{t}, \pi_{t}$ is defined as $x_{t}=\frac{X_{t}}{P_{T t}}$ and $V\left(w_{1}, s, d\right)$ is given by

$$
\begin{aligned}
& V\left(w_{1}, s, d\right)=\max _{C_{N 2}, C_{T 2}, C_{T 3}, d^{\prime}} \omega_{T} \log C_{T 2}+\omega_{N} \log C_{N 2}+\beta \omega_{T} \log C_{T 3}, \\
& \text { s.t. } p_{N 2} C_{N 2}+C_{T 2}=w_{2} h_{2}+\pi_{2}+(1-s) y_{T 2}-d+\frac{d^{\prime}}{1+r}, \\
& h_{2}=\min \left\{\bar{h},\left(\frac{\alpha p_{N 2} z_{2}}{\gamma w_{1}}\right)^{\frac{1}{1-\alpha}}\right\} \\
& C_{T 3}=(1-s) y_{T 3}-d^{\prime} .
\end{aligned}
$$

This setup generates an aggregate demand externality when the nominal wage constraint binds in period 2. To see this, note that $\frac{\partial V}{\partial w_{1}}<0$ when $h_{2}=\left(\frac{\alpha p_{N 2} z_{2}}{\gamma w_{1}}\right)^{\frac{1}{1-\alpha}}$. Private agents do not take into account the general equilibrium effect through $w_{1}$ whereas the social planner does. In that case, the allocations under a competitive equilibrium differs from that chosen by a social planner.

\section{Competitive Equilibrium}

We solve for the competitive equilibrium backwards from period 2. There are two states of world at period 2, one with a binding wage constraint and the other with a slack wage constraint. As there is no friction in the debt market in period 2, optimal consumption smoothing requires that $C_{T 2}=\frac{(1-s)\left(y_{T 2}+\frac{y_{T 3}}{1+r}\right)-d}{1+\beta}$. The amount of tradable consumption (aggregate demand) also implies that the maximum labor demand given the binding wage constraint is $\hat{h}_{2}=\frac{\alpha \omega_{N}}{\gamma w_{1} \omega_{T}} C_{T 2}$. Clearly, when $\hat{h}_{2}>\bar{h}$, the higher aggregate demand needs more labor that exceeds the maximum amount of labor in the economy. In equilibrium, the nominal wage will be higher than the lower bound $\gamma w_{1}$ and there is full employment. When $\hat{h}_{2}<\bar{h}$, the aggregate demand in the economy is insufficient to absorb full employment and there will be involuntary unemployed labor. The key friction is the wage constraint that prevents a fall in nominal wage as to stimulate aggregate demand.

Period-1 Equilibrium In period 1, the agent chooses $s$ and $d$ to smooth tradable consump- 
tion $C_{T 1}$. The optimal conditions are given by

$$
\begin{aligned}
& \frac{\omega_{T}}{C_{T 1}} p_{e}=\beta E\left[\frac{\omega_{T}}{C_{T 2}} y_{T 2}+\beta \frac{\omega_{T}}{C_{T 3}} y_{T 3}\right] \\
& \frac{\omega_{T}}{C_{T 1}}=\beta(1+r) E\left[\frac{\omega_{T}}{C_{T 2}}\right]
\end{aligned}
$$

The first condition is consistent with an interior solution with $s \in(0,1)$. Otherwise, $s=$ 1 when $\frac{\omega_{T}}{C_{T 1}} p_{e}>\beta E\left[\frac{\omega_{T}}{C_{T 2}} y_{T 2}+\beta \frac{\omega_{T}}{C_{T 3}} y_{T 3}\right]$ and $s=0$ when $\frac{\omega_{T}}{C_{T 1}} p_{e}<\beta E\left[\frac{\omega_{T}}{C_{T 2}} y_{T 2}+\beta \frac{\omega_{T}}{C_{T 3}} y_{T 3}\right]$.

When $\theta=0$ and $p_{e}=y_{1}$, the equilibrium features equity flow only, i.e. $s=1$. To see this, we note the following:

$$
\begin{aligned}
& \frac{\omega_{T}}{C_{T 1}} y_{1}-\beta E\left[\frac{\omega_{T}}{C_{T 2}} y_{T 2}+\beta \frac{\omega_{T}}{C_{T 3}} y_{T 3}\right] \\
& =\beta(1+r) E\left[\frac{\omega_{T}}{C_{T 2}}\right] y_{1}-\beta E\left[\frac{\omega_{T}}{C_{T 2}} y_{T 2}+\beta \frac{\omega_{T}}{C_{T 3}} y_{T 3}\right] \\
& =\beta E\left[\frac{\omega_{T}}{C_{T 2}}\left(\frac{y+y}{2}+\frac{y_{T 3}}{1+r}-y_{T 2}\right)-\beta \frac{\omega_{T}}{C_{T 3}} y_{T 3}\right] \\
& =\beta E\left[\frac{\omega_{T}}{C_{T 2}}\left(\frac{y+\bar{y}}{2}-y_{T 2}\right)\right]=-\beta \operatorname{cov}\left(\frac{\omega_{T}}{C_{T 2}}, y_{T 2}\right)>0
\end{aligned}
$$

Therefore, the domestic agents issue only equity when $\theta=0$. By doing so, the risk in the tradable sector has been shifted completely to the (risk-neutral) international investors. There is only one state of the world in period 2 . Under a mild condition such that $\beta(1+r)>\gamma$, the period- 2 equilibrium features full employment regards of the value of the tradable income. This means no aggregate demand externality in the economy. In general, however, when $\theta$ is within the region of $[0,1]$, the economy features both equity and debt issuance. By the same argument as in Section F.3, both the capital structure in the economy and the severity of externality depend on $\theta$.

\section{The Social Planner's Problem}

The social planner internalizes the aggregate demand externality and chooses the allocation differently. Her problem can be written as follows. 


$$
\begin{array}{ll}
W^{S P} & =\max _{C_{T 1}, s, d} \omega_{T} \log C_{T 1}+\omega_{N} \log z_{1} \bar{h}^{\alpha}+\beta E_{1}\left[V^{S P}\left(C_{T 1}, s, d\right)\right], \\
\text { s.t. } & C_{T 1}=s p_{e}+\frac{d}{1+r}
\end{array}
$$

where $V^{S P}\left(C_{T 1}, s, d\right)$ is defined as

$$
\begin{aligned}
& V^{S P}\left(C_{T 1}, s, d\right)=\max _{C_{T 2}, C_{T 3}, d^{\prime}} \omega_{T} \log C_{T 2}+\omega_{N} \log z_{2} h_{2}^{\alpha}+\beta \omega_{T} \log C_{T 3}, \\
& \text { s.t. } C_{T 2}=(1-s) y_{T 2}-d+\frac{d^{\prime}}{1+r}, \\
& h_{2}=\bar{h} \min \left\{1, \frac{C_{T 2}}{\gamma C_{T 1}}\right\} \\
& C_{T 3}=(1-s) y_{T 3}-d^{\prime} .
\end{aligned}
$$

Period-2 Equilibrium Similar to the competitive equilibrium, there are two states of the world. The first is with full employment, i.e. $C_{T 2}>\gamma C_{T 1}$. The allocation of the social planner coincides with the competitive equilibrium. However, in the second state of the world when there is involuntary unemployment, i.e. $C_{T 2}<\gamma C_{T 1}$, the social planner's optimality condition implies that

$$
C_{T 2}=\frac{1}{1+\beta /\left(1+\alpha \omega_{N} / \omega_{T}\right)}\left[(1-s)\left(y_{T 2}+\frac{y_{T 3}}{1+r}\right)-d\right]>\frac{1}{1+\beta}\left[(1-s)\left(y_{T 2}+\frac{y_{T 3}}{1+r}\right)-d\right]
$$

In other words, the social planner chooses a higher level of consumption so as to stimulate the aggregate demand during the involuntary unemployment state.

Period-1 Equilibrium The optimal conditions imply that

$$
\begin{aligned}
& \lambda^{S P}=\frac{\omega_{T}}{C_{T 1}}+\beta E\left[\frac{\partial V^{S P}}{\partial C_{T 1}}\right] \\
& \lambda^{S P} p_{e}=\beta E\left[\lambda_{2}^{S P} y_{T 2}+\beta \frac{\omega_{T}}{C_{T 3}} y_{T 3}\right] \\
& \lambda^{S P}=\beta(1+r) E\left[\lambda_{2}^{S P}\right]
\end{aligned}
$$

where $\lambda^{S P}$ and $\lambda_{2}^{S P}$ are the Lagrangian multipliers associated with the budget constraints in periods 1 and 2 , respectively.

To understand the source of inefficiency, we assume that the social planner's allocation can be implemented by a capital control tax with a lump sum transfer. The budget 
constraints for private agents are then changed into

$$
\begin{aligned}
& p_{N 1} C_{N 1}+C_{T 1}=w_{1} \bar{h}+\pi_{1}+\left[s p_{e}\left(1-\tau_{e}\right)+\frac{d}{1+r}\left(1-\tau_{d}\right)+T\right] \\
& p_{N 2} C_{N 2}+C_{T 2}=w_{2} h_{2}+\pi_{2}+(1-s) y_{T 2}-d+\frac{d^{\prime}}{1+r}\left(1-\tau_{d^{\prime}}\right)+T^{\prime}
\end{aligned}
$$

with $T=\tau_{e} s p_{e}+\frac{d}{1+r} \tau_{d}$ and $T^{\prime}=\frac{d^{\prime}}{1+r} \tau_{d^{\prime}}$.

To implement the social planner's allocation, the taxes are given by

$$
\begin{aligned}
\tau_{e} & =\frac{\beta E\left[\alpha \frac{\omega_{N}}{C_{T 2}} y_{T 2} \mu-p_{e} \frac{\partial V^{S P}}{\partial C_{T 1}}\right]}{p_{e} \frac{\omega_{T}}{C_{T 1}}}>0 \\
\tau_{d} & =\frac{\beta E\left[(1+r) \alpha \frac{\omega_{N}}{C_{T 2}} \mu-\frac{\partial V}{\partial C_{T 1}}\right]}{\frac{\omega_{T}}{C_{T 1}}}>0 \\
\tau_{d^{\prime}} & =-\alpha \frac{\omega_{N}}{\omega_{T}} \mu<0
\end{aligned}
$$

where $\mu=1$ in the involuntary unemployment state and $\mu=0$ in the full employment state. Moreover, $\tau_{d}>\tau_{e}$. Therefore, the optimal policy includes a macroprudential capital tax on both debt and equity in period 1 and a negative capital control tax on debt in the involuntary unemployment state in period 2 .

\section{E Equity Issuance During Crises (online only)}

In this extension, we allow for equity issuance in the intermediate period. A key insight is a possible role for ex post intervention because pecuniary externality affects two decision margins in the second period.

Suppose that in the second period, the economy can issue an additional share of equity $s^{\prime} \in[0,1-s]$ to foreign investors. Since the equity issuance is subject to expropriation risk $\theta$, the share of equity is priced at $(1-\theta) \frac{y_{3}}{1+r}$. The budget constraints in periods 2 and 3 become

$$
\begin{aligned}
& p C_{N 2}+C_{T 2}=\underbrace{(1-s) y_{2}-d}_{m}+p y_{N 2}+\frac{d^{\prime}}{1+r}+s^{\prime}(1-\theta) \frac{y_{3}}{1+r} \\
& C_{T 3}=y_{3}-d^{\prime}-\left(s+s^{\prime}\right) y_{3}
\end{aligned}
$$


The financial constraint in period 2 is unchanged, i.e.

$$
\frac{d^{\prime}}{1+r} \leq \phi\left((1-s) y_{2}+p y_{N 2}\right)
$$

The economy can choose equity and debt financing to smooth consumption in the second period. However, the use of equity financing depends on the quality of domestic institutions. Consider the case where $\theta=0$, i.e. very good domestic institution. In the second period, the economy always uses equity financing as opposed to debt financing since equity financing does not lead to a binding financial constraint. Therefore, there will be no case for debt financing, the same insight as in the benchmark model. However, equity financing is never used in equilibrium when the institution quality is poor (for example, $\theta=1$ ). By continuity, there will be an optimal capital structure in the second period depending on $\theta$.

Proposition 11. When the economy is allowed to issue equity in the second period, it chooses to do so when the constraint binds in the second period. However, the economy chooses too little equity financing due to the pecuniary externality, which justifies an expost intervention. There will still be an over-borrowing in the first period as in the benchmark economy. To correct the externality, the social planner needs to use both ex-ante and ex-post interventions.

Proof. Proof is given in Appendix F.8.

The possibility of equity issuance in the second period allows a role for ex-post intervention since the pecuniary externality affects two decision margins in the second period when the constraint binds. Unlike the previous literature which allows for only debt financing (Bianchi (2011) and Jeanne and Korinek (2018)), introducing equity financing allows the social planner to use ex-post intervention to change the composition of external financing when the constraint binds. In particular, the social planner favors equity financing as it provides better risk-sharing and suffers less pecuniary externality than debt financing. Nevertheless, the use of ex-post intervention cannot completely eliminate the pecuniary externality, which calls for a use of ex-ante policy intervention in equilibrium.

It is also worth pointing out that the feature of an ex-post intervention is different from the existing form of ex-post intervention in the literature such as Benigno et al. (2013), Ma (2020) and Jeanne and Korinek (2020). Our ex-post intervention is used to change the composition of external financing in order to reduce the cost of a binding constraint, while it is used in Benigno et al. (2016) to change the composition of labor supplies between the tradable and non-tradable sectors or in Ma (2020) the composition of consumption versus investment. The ex-post intervention takes the form of a fiscal transfer in Jeanne and Korinek (2020) but a tax on capital flows in our case. 


\section{F Proofs (online only)}

\section{F.1 Proof of Proposition 2}

Proof. When the constraint is slack, the following condition holds.

$$
d^{\prime}=\frac{(1-s) y_{3}-\beta(1+r) m}{1+\beta}
$$

The constraint is slack iff

$$
\frac{d^{\prime}}{1+r} \leq \phi\left(\frac{\omega_{N}}{\omega_{T}} C_{T 2}+(1-s) y_{2}\right)=\phi\left(\frac{\omega_{N}}{\omega_{T}}\left(m+\frac{d^{\prime}}{1+r}\right)+(1-s) y_{2}\right) \leq \frac{\phi \frac{\omega_{N}}{\omega_{T}} m+\phi(1-s) y_{2}}{1-\phi \frac{\omega_{N}}{\omega_{T}}}
$$

Equivalently, the constraints bind if

$$
\frac{d}{1-s}>\frac{y_{2}\left(\frac{\beta}{1+\beta}+\frac{\phi / \omega_{T}}{1-\phi \frac{\omega_{N}}{\omega_{T}}}\right)-\frac{y_{3}}{(1+\beta)(1+r)}}{\frac{\beta}{1+\beta}+\frac{\phi \frac{\omega_{N}}{\omega_{T}}}{1-\phi \frac{\omega_{N}}{\omega_{T}}}}
$$

\section{F.2 Proof of Proposition 3}

Proof. When $\theta=0$, the optimality conditions for $d, s$ and $d^{\prime}$ are given by

$$
\begin{aligned}
& \frac{\omega_{T}}{C_{T 1}}=\beta(1+r) E_{1}\left[\frac{\omega_{T}}{C_{T 2}}\right] \\
& -\frac{\omega_{T}}{C_{T 1}} y_{1}+\beta E_{1}\left[\frac{\omega_{T}}{C_{T 2}} y_{2}+\mu \phi y_{2}+\beta \frac{\omega_{T}}{C_{T 3}} y_{3}\right] \leq 0 \\
& \frac{\omega_{T}}{C_{T 2}}=\beta(1+r) \frac{\omega_{T}}{C_{T 3}}+\mu
\end{aligned}
$$

where equation (13) holds with inequality when $s=1$.

By plugging the optimality conditions (12) and (14) into (13), the LHS of equation (13) becomes

$$
\beta E_{1}\left[\frac{\omega_{T}}{C_{T 2}}\left(y_{2}-\frac{y+\bar{y}}{2}\right)+\mu\left(\phi y_{2}-\frac{y_{3}}{1+r}\right)\right]
$$


which is negative because

$$
\begin{aligned}
& E_{1}\left[\frac{\omega_{T}}{C_{T 2}}\left(y_{2}-\frac{y+\bar{y}}{2}\right)\right]=\operatorname{cov}\left(\frac{\omega_{T}}{C_{T 2}}, y_{2}\right)<0, \\
& E_{1}\left[\mu\left(\phi y_{2}-\frac{y_{3}}{1+r}\right)\right]=E_{1}\left[\frac{\mu}{1-s}\left(-\frac{C_{T 3}}{1+r}-\phi \frac{\omega_{N}}{\omega_{T}} C_{T 2}\right)\right] \leq 0
\end{aligned}
$$

where $\mu$ is the Lagrangian multiplier associated with the financial constraint (2). $\operatorname{cov}\left(\frac{\omega_{T}}{C_{T 2}}, y_{2}\right)<$ 0 simply because

$$
\begin{aligned}
& C_{T 2}=\frac{(1-s) y_{2}-d+(1-s) \frac{y_{3}}{1+r}}{1+\beta}, \text { if the constraint is slack; } \\
& C_{T 2}=\frac{(1+\phi)(1-s) y_{2}-d}{1-\phi \frac{\omega_{N}}{\omega_{T}}}, \text { if the constraint binds. }
\end{aligned}
$$

Therefore, the optimal equity share $s$ is 1 .

\section{F.3 Proof of Proposition 4}

Proof. The optimality conditions for $d$ and $s$ are given by

$$
\begin{aligned}
& \frac{\omega_{T}}{C_{T 1}}=\beta(1+r) E\left[\frac{\omega_{T}}{C_{T 2}}\right] \\
& \frac{\omega_{T}}{C_{T 1}} y_{1}(1-\theta)-\beta E_{1}\left[\frac{\omega_{T}}{C_{T 2}} y_{2}+\mu \phi y_{2}+\beta \frac{\omega_{T}}{C_{T 3}} y_{3}\right]=0
\end{aligned}
$$

From condition (16), one can define $d^{*}=D(s, \theta)$. By the implicit function theorem,

$$
\begin{aligned}
& \frac{\partial d^{*}}{\partial s}=-\frac{-\frac{\omega_{T}}{C_{T 1}^{2}}(1-\theta) y_{1}-\beta(1+r) E\left[-\frac{\omega_{T}}{C_{T 2}^{2}} \frac{\partial C_{T 2}}{\partial s}\right]}{-\frac{\omega_{T}}{C_{T 1}^{2}} \frac{1}{1+r}-\beta(1+r) E\left[-\frac{\omega_{T}}{C_{T 2}^{2}} \frac{\partial C_{T 2}}{\partial d}\right]}<0 \\
& \frac{\partial d^{*}}{\partial \theta}=-\frac{-\frac{\omega_{T}}{C_{T 1}^{2}}\left(-s y_{1}\right)}{-\frac{\omega_{T}}{C_{T 1}^{2}} \frac{1}{1+r}-\beta(1+r) E\left[-\frac{\omega_{T}}{C_{T 2}^{2}} \frac{\partial C_{T 2}}{\partial d}\right]}>0
\end{aligned}
$$

where it follows that $\frac{\partial C_{T 2}}{\partial s}<0$ and $\frac{\partial C_{T 2}}{\partial d}<0$. 
We define the following function to capture the optimality condition for equity issuance

$$
F\left(s, d^{*}, \theta\right)=-\frac{\omega_{T}}{C_{T 1}} y_{1}(1-\theta)+\beta E_{1}\left[\frac{\omega_{T}}{C_{T 2}} y_{2}+\mu \phi y_{2}+\beta \frac{\omega_{T}}{C_{T 3}} y_{3}\right]
$$

Realize that $\frac{\partial F\left(s, d^{*}, \theta\right)}{\partial s}>0, \frac{\partial F\left(s, d^{*}, \theta\right)}{\partial d^{*}}>0$ and $\frac{\partial F\left(s, d^{*}, \theta\right)}{\partial \theta}>0$, where the first two relationships are implied by the concavity of the problem. Therefore, we have $\frac{\partial s}{\partial d^{*}}=-\frac{\frac{\partial F\left(s, d^{*}, \theta\right)}{\partial d^{*}}}{\frac{\partial F\left(s, d^{*}, \theta\right)}{\partial s}}<0$ and $\frac{\partial s}{\partial \theta}=-\frac{\frac{\partial F\left(s, d^{*}, \theta\right)}{\partial \theta}}{\frac{\partial F\left(s, d^{*}, \theta\right)}{\partial s}}<0$

The optimality condition for equity issuance implies that

$$
\begin{aligned}
& s^{*}=1, \text { if } F\left(s, d^{*}, \theta\right)<0 \text { for all } s \in[0,1] \\
& s^{*}=0, \text { if } F\left(s, d^{*}, \theta\right)>0 \text { for all } s \in[0,1] \\
& s^{*} \in(0,1), \text { if there exist } s \in[0,1] \text { such that } F\left(s, d^{*}, \theta\right)=0
\end{aligned}
$$

Since $F\left(s, d^{*}, 0\right)<0$ as shown in F.2 and $F\left(s, d^{*}, 1\right)>0$ for $\forall s \in[0,1]$, by continuity, there exists a $\bar{\theta}$ such that $F\left(s, d^{*}, \bar{\theta}\right)=0$ for $s=0$. When $\theta>\bar{\theta}, F\left(s, d^{*}, \theta\right)>F\left(0, d^{*}, \theta\right)>$ $F\left(0, d^{*}, \bar{\theta}\right)=0$ for all $s \in[0,1]$. In this case, the optimal level of $s$ is 0 . The equilibrium features only debt and no equity issuance.

Similarly, since there exists a $\underline{\theta}$ such that $F\left(s, d^{*}, \underline{\theta}\right)=0$ for $s=1$. When $\theta<\underline{\theta}$, $F\left(s, d^{*}, \theta\right)<F\left(1, d^{*}, \theta\right)<F\left(1, d^{*}, \underline{\theta}\right)=0$ for all $s \in[0,1]$. In this case, the optimal level of $s$ is 1 . The equilibrium features only equity and no debt.

When $\theta \in(\underline{\theta}, \bar{\theta})$, there is an interior solution for equity issuance $s$. As $\theta$ decreases, the optimal level of equity share $s$ increases and debt $d$ decreases as implied by $\frac{\partial s}{\partial \theta}<0$ and $\frac{\partial d^{*}}{\partial \theta}>0$. In equilibrium, it is consistent with $\frac{\partial s}{\partial d^{*}}<0$ and $\frac{\partial d^{*}}{\partial s}<0$.

One can show that a higher $\theta$ leads to a higher $\frac{d}{1-s}$. To see this, one recognizes that equation (16) can be written as a function of $s$ and $\frac{d}{1-s}$.

$$
\frac{\omega_{T}}{(1-\theta) y_{1}-(1-s)\left((1-\theta) y_{1}-\frac{d /(1-s)}{1+r}\right)}=\beta(1+r) E\left[\frac{\omega_{T}}{C_{T 2}}\right]
$$

$C_{T 2}$ is a decreasing function of $d /(1-s)$ and an increasing function of $1-s$ since $C_{T 2}=$ $\frac{(1-s)\left(\frac{y_{3}}{1+r}+y_{2}-d /(1-s)\right)}{1+\beta}$ if unconstrained and $C_{T 2}=\frac{(1-s)\left((1+\phi) y_{2}-d /(1-s)\right)}{1-\phi \frac{\omega_{N}}{\omega_{T}}}$ if constrained. Therefore, following a higher value of $\theta$, a higher $1-s$ raises the value of the LHS while reducing that of the RHS of equation (18), leading to a higher $d /(1-s)$.

Therefore, in equilibrium a higher $\theta$ leads to a lower $s$, a higher $d$ and $d /(1-s)$, which implies a higher leverage ratio $\frac{d /(1+r)}{s(1-\theta) y_{1}+d /(1+r)}$. Notice that the probability of binding con- 
straints depends on the level of $d /(1-s)$. A higher level of $d /(1-s)$ implies a higher probability of binding constraints due to equation (11).

\section{F.4 Proof of Proposition 5}

Proof. Given the definition of $V^{S P}\left(m, s, y_{2}\right)$, we have the following

$$
\begin{aligned}
V^{S P}\left(m, s, y_{2}\right)= & \max _{C_{T 2}, d^{\prime}, C_{T 3}} \omega_{N} \log y_{N 2}+\omega_{T} \log C_{T 2}+\beta \omega_{T} \log C_{T 3} \\
\text { s.t. } \quad & C_{T 2}=m+\frac{d^{\prime}}{1+r}, \\
& C_{T 3}+d^{\prime}=(1-s) y_{3}, \\
& \frac{d^{\prime}}{1+r} \leq \phi\left(\frac{\omega_{N}}{\omega_{T}} C_{T 2}+(1-s) y_{2}\right) .
\end{aligned}
$$

The optimality conditions are given by

$$
\begin{aligned}
& \lambda=\frac{\omega_{T}}{C_{T 2}}+\phi \mu \frac{\omega_{N}}{\omega_{T}} \\
& \lambda=\mu+\beta(1+r) \frac{\omega_{T}}{C_{T 3}}
\end{aligned}
$$

where $\lambda$ and $\mu$ are the Lagrangian multipliers for the budget constraint (19) and collateral constraint (20).

When the constraint is slack, the following condition holds.

$$
d^{\prime}=\frac{(1-s) y_{3}-\beta(1+r) m}{1+\beta}
$$

The constraint is slack iff

$$
\frac{d^{\prime}}{1+r} \leq \phi\left(\frac{\omega_{N}}{\omega_{T}} C_{T 2}+(1-s) y_{2}\right)=\phi\left(\frac{\omega_{N}}{\omega_{T}}\left(m+\frac{d^{\prime}}{1+r}\right)+(1-s) y_{2}\right) \leq \frac{\phi \frac{\omega_{N}}{\omega_{T}} m+\phi(1-s) y_{2}}{1-\phi \frac{\omega_{N}}{\omega_{T}}}
$$

Equivalently, the constraints bind if

$$
\frac{d}{1-s}>\frac{y_{2}\left(\frac{\beta}{1+\beta}+\frac{\phi / \omega_{T}}{1-\phi \frac{\omega_{N}}{\omega_{T}}}\right)-\frac{y_{3}}{(1+\beta)(1+r)}}{\frac{\beta}{1+\beta}+\frac{\phi \frac{\omega_{N}}{\omega_{T}}}{1-\phi \frac{\omega_{N}}{\omega_{T}}}}
$$


Since expressions (11) and (21) are identical, there is no difference between the private agents and the social planner in the condition for the constraints to be binding. The allocation is given by

$$
\begin{aligned}
& C_{T 2}=\frac{m+(1-s) \frac{y_{3}}{1+r}}{1+\beta}, \text { if slack } \\
& C_{T 2}=\frac{m+\phi(1-s) y_{2}}{1-\phi \frac{\omega_{N}}{\omega_{T}}}, \text { if constrained }
\end{aligned}
$$

This is the same as that in the competitive equilibrium, which is characterized in $V\left(m, s, y_{1}\right)$.

By the envelope theorem, we have

$$
\begin{aligned}
& \frac{\partial V^{S P}\left(m, s, y_{2}\right)}{\partial m}=\frac{\omega_{T}}{C_{T 2}}+\phi \mu \frac{\omega_{N}}{\omega_{T}}, \\
& \frac{\partial V^{S P}\left(m, s, y_{2}\right)}{\partial s}=-\phi y_{2} \mu-\beta \frac{\omega_{T}}{C_{T 3}} y_{3},
\end{aligned}
$$

As $\mu>0$, we see that $\frac{\partial V^{S P}\left(m, s, y_{2}\right)}{\partial m}>\frac{\partial V\left(m, s, y_{2}\right)}{\partial m}$.

\section{F.5 Proof of Proposition 6 and 7}

Proof. The optimality conditions for $d$ and $s$ are given, respectively, by

$$
\begin{aligned}
& \frac{\omega_{T}}{C_{T 1}}=\beta(1+r) E\left[\frac{\omega_{T}}{C_{T 2}}+\phi \mu \frac{\omega_{N}}{\omega_{T}}\right] \\
& \frac{\omega_{T}}{C_{T 1}} y_{1}(1-\theta)=\beta E_{1}\left[\left(\frac{\omega_{T}}{C_{T 2}}+\phi \mu \frac{\omega_{N}}{\omega_{T}}\right) y_{2}+\mu \phi y_{2}+\beta \frac{\omega_{T}}{C_{T 3}} y_{3}\right]
\end{aligned}
$$

Using the same proof as in Appendix F.3, one can show the following: (1) There exists a $\bar{\theta}^{S P}$ such that there will be only debt issuance when $\theta>\bar{\theta}^{S P}$; (2) There exists a $\underline{\theta}^{S P}$ such that there will be only equity issuance when $\theta<\underline{\theta}^{S P}$; (3) When $\theta \in\left(\underline{\theta}^{S P}, \bar{\theta}^{S P}\right)$, there will be a mixture of equity and debt. Furthermore, a higher $\theta$ leads to a lower $s$, a higher $d$ and $d /(1-s)$, which implies a higher leverage ratio $\frac{d /(1+r)}{s(1-\theta) y_{1}+d /(1+r)}$. Notice that the probability of the constraints becoming binding depends on the level of $d /(1-s)$ : The higher the value of $d /(1-s)$, the greater the probability of binding constraints due to equation (21).

Suppose we impose capital control taxes on debt and equity, $\tau^{d}$ and $\tau^{s}$, respectively, the 
first-period budget constraint becomes

$$
C_{T 1}=\left(1-\tau^{s}\right) s(1-\theta) y_{1}+\left(1-\tau^{d}\right) \frac{d}{1+r}+T
$$

where $T=\tau^{s} s(1-\theta) y_{1}+\tau^{d} \frac{d}{1+r}$.

To close the gap between the social planner's allocation and that of the private agents, we have to have

$$
\begin{aligned}
\tau^{d} & =\frac{\beta(1+r) E\left[\phi \mu \frac{\omega_{N}}{\omega_{T}}\right]}{\frac{\omega_{T}}{C_{T 1}}}>0 \\
\tau^{s} & =\frac{\beta E\left[\phi \mu \frac{\omega_{N}}{\omega_{T}} y_{2}\right]}{\frac{\omega_{T}}{C_{T 1}}(1-\theta) y_{1}}>0
\end{aligned}
$$

It can be shown that $\tau^{d}>\tau^{s}$ since

$$
\tau^{d}-\tau^{s}=\frac{\beta(1+r) \phi \frac{\omega_{N}}{\omega_{T}} E\left[\mu\left((1-\theta) y_{1}-\frac{y_{2}}{1+r}\right)\right]}{\frac{\omega_{T}}{C_{T 1}}(1-\theta) y_{1}}
$$

and

$$
\begin{aligned}
& E\left[\mu\left((1-\theta) y_{1}-\frac{y_{2}}{1+r}\right)\right] \\
= & E[\mu] E\left[\left((1-\theta) y_{1}-\frac{y_{2}}{1+r}\right)\right]+\operatorname{cov}\left(\mu,\left((1-\theta) y_{1}-\frac{y_{2}}{1+r}\right)\right)>0 .
\end{aligned}
$$

$E\left[\left((1-\theta) y_{1}-\frac{y_{2}}{1+r}\right)\right]$ has to be positive for an positive amount of equity to be issued in equilibrium. $\operatorname{cov}\left(\mu,\left((1-\theta) y_{1}-\frac{y_{2}}{1+r}\right)\right)>0$ since a lower level of $y_{2}$ is associated with a tighter borrowing constraint, i.e. a higher value of $\mu$.

Given that $\tau^{d}>\tau^{s}$, the wedge in the debt financing is higher than that in the equity financing. As a result, the social planner chooses a lower overall level of external financing $C_{T 1}$, and a smaller component of debt than equity financing. Therefore, the debt to income ratio of $d /(1-s)$ should be lower in the social planner's allocation, resulting in a lower probability of crises.

For $\theta<\underline{\theta}^{S P}$, the decentralized equilibrium features only equity financing. In this case, there is no difference between the social planner's choice and the decentralized equilibrium, and the collateral constraint does not bind. In comparison, for $\theta \geq \bar{\theta}^{S P}$, the decentralized equilibrium features only debt financing. There is a wedge between the private agents' and the social planner's allocations. By continuity, there exists a $\theta^{*}$ such that the allocation 
under the competitive equilibrium is constrained efficient when $\theta<\theta^{*}$, and constrained inefficient when $\theta>\theta^{*}$. Moreover, one can see that $\theta^{*}>\underline{\theta}^{S P}$. Notice that only when $\theta>\underline{\theta}^{S P}$, there will be debt issuance. The inefficiency arises only when $d /(1-s)$ is high enough. Consider $\theta$ is only marginally higher than $\underline{\theta}^{S P}$ such that the equilibrium $d$ is lower enough. In that case, there is no binding constraint in the economy and also inefficiency. Therefore, one get $\theta^{*}>\underline{\theta}^{S P}$ and $\theta^{*}<\bar{\theta}^{S P}$.

\section{F.6 Proof of Proposition 8}

The problem can be written as

$$
\begin{aligned}
& \max _{d, D} \omega_{T} \log C_{T 1}+\beta E_{1}\left[V\left(d, D, y_{2}\right)\right], \\
& \text { s.t. } C_{T 1}=\frac{d}{1+r}+\frac{D}{(1+r)^{2}}(1-\theta)
\end{aligned}
$$

where $V\left(d, D, y_{2}\right)$ is given by

$$
\begin{aligned}
V\left(d, D, y_{2}\right)= & \max _{C_{N 2}, C_{T 2}, C_{T 3}, d^{\prime}} \omega_{T} \log C_{T 2}+\omega_{N} \log C_{N 2}+\beta \omega_{T} \log C_{T 3}, \\
\text { s.t. } \quad & p C_{N 2}+C_{T 2}=y_{2}-d+p y_{N 2}+\frac{d^{\prime}}{1+r} \\
& \frac{d^{\prime}}{1+r} \leq \phi\left(y_{2}+p y_{N 2}\right) \\
& C_{T 3}=y_{3}-d^{\prime}-D
\end{aligned}
$$

The optimality conditions are given by

$$
\begin{aligned}
& \operatorname{FOC}\left(C_{T 2}\right): \lambda=\frac{\omega_{T}}{C_{T 2}} \\
& \operatorname{FOC}\left(d^{\prime}\right): \lambda=\mu+\beta(1+r) \frac{\omega_{T}}{C_{T 3}}
\end{aligned}
$$

where $\lambda$ and $\mu$ are the Lagrangian multipliers associated with equations (24) and (25), respectively.

In the first period, the optimality conditions for $d$ and $D$ are given by

$$
\begin{aligned}
& \frac{\omega_{T}}{C_{T 1}}=\beta(1+r) E_{1}\left[\frac{\omega_{T}}{C_{T 2}}\right] \\
& \frac{\omega_{T}}{C_{T 1}}(1-\theta)=\beta^{2}(1+r)^{2} E_{1}\left[\frac{\omega_{T}}{C_{T 3}}\right]
\end{aligned}
$$


Similar to the benchmark economy, there will be an equilibrium capital structure in which the ratio of $d$ and $D$ depends on $\theta$. Define the marginal benefit function of long-term debt as follows

$$
\begin{aligned}
M B(d, D, \theta) & \equiv \frac{\omega_{T}}{C_{T 1}}(1-\theta)-\beta^{2}(1+r)^{2} E_{1}\left[\frac{\omega_{T}}{C_{T 3}}\right] \\
& =-\theta \frac{\omega_{T}}{C_{T 1}}+\beta(1+r) E_{1}[\mu]
\end{aligned}
$$

where the last relationship combines two optimality conditions.

From the marginal benefit function, it is easy to see that $M B(d, D, 0)>0>M B(d, D, 1)$ for any $d, D \geq 0$. Furthermore, we have $M B_{d}>0, M B_{D}>0$ and $M B_{\theta}<0$. Using these relationships, we find that the optimal level of short-term debt $d$ is 0 when $\theta=0$ while the longterm debt $D$ is 0 when $\theta=1$. By continuity, there will exists a $\underline{\theta}$ such that $M B(0, D, \underline{\theta})=0$. In this case, for any $\theta<\underline{\theta}, M B(d, D, \theta)>M B(d, D, \underline{\theta})>M B(0, D, \underline{\theta})=0$, which implies that $d^{*}=0$. In this region, only long-term debt will be issued. Similarly, one can define $\bar{\theta}$ such that $M B(d, D, \bar{\theta})=0$. In this case, for any $\theta>\bar{\theta}, D^{*}=0$ as $M B(d, D, \theta)<0$. Therefore, an interior solution exists in the region of $(\underline{\theta}, \bar{\theta})$. Using the same logic in Appendix F.3, one can show that a higher $\theta$ in this region leads to a higher $d$ and a lower $D$.

The case for policy intervention is similar to the benchmark economy since the pecuniary externality only applies to the short term debt. Specifically, the social planner values $d$ differently from private agents. By the same logic as in Appendix F.5, there is overborrowing in the decentralized economy and the social planner uses capital controls to correct the inefficiency. To see this, define a social planner as follows.

$$
\begin{aligned}
V^{S P}\left(d, D, y_{2}\right)= & \max _{C_{T 2}, C_{T 3}, d^{\prime},} \omega_{T} \log C_{T 2}+\omega_{N} \log y_{N 2}+\beta \omega_{T} \log C_{T 3}, \\
\text { s.t. } \quad & C_{T 2}=y_{2}-d+\frac{d^{\prime}}{1+r} \\
& \frac{d^{\prime}}{1+r} \leq \phi\left(y_{2}+\frac{\omega_{N}}{\omega_{T}} C_{T 2}\right) \\
& C_{T 3}=y_{3}-d^{\prime}-D
\end{aligned}
$$

The optimality conditions of $d$ and $\mathrm{D}$ for the social planner are given by

$$
\begin{aligned}
& \frac{\omega_{T}}{C_{T 1}}=\beta(1+r) E_{1}\left[\lambda^{S P}\right]=\beta(1+r) E_{1}\left[\frac{\omega_{T}}{C_{T 2}}+\phi \frac{\omega_{N}}{\omega_{T}} \mu^{S P}\right] \\
& \frac{\omega_{T}}{C_{T 1}}(1-\theta)=\beta^{2}(1+r)^{2} E_{1}\left[\frac{\omega_{T}}{C_{T 3}}\right]
\end{aligned}
$$


Because the pecuniary externality only affects the decision margin for short-term debt $d$, one only need one capital controls to correct the inefficiency. Specifically, we introduce a tax $\tau_{d}$ on short term debt and a lump-sum transfer $T$ as follows.

$$
C_{T 1}=\left(1-\tau^{d}\right) \frac{d}{1+r}+(1-\theta) \frac{D}{(1+r)^{2}}+T
$$

where $T=\tau^{d} \frac{d}{1+r}$.

We need to choose $\tau_{d}=\frac{\beta(1+r) E_{1}\left[\phi \frac{\omega_{N}}{\omega_{T}} \mu^{S P}\right]}{\frac{\omega_{T}}{C_{T 1}}}>0$ to close the gap between the social planner and private agents.

\section{F.7 Proof of Proposition 9}

The problem can be written as

$$
\begin{aligned}
& \max _{d, l} \omega_{T} \log C_{T 1}+\beta E_{1}\left[V\left(d, l, y_{2}\right)\right], \\
& \text { s.t. } C_{T 1}=\frac{d}{1+r}+l(1-\theta)
\end{aligned}
$$

where $V\left(d, l, y_{2}\right)$ is given by

$$
\begin{aligned}
V\left(d, l, y_{2}\right)= & \max _{C_{N 2}, C_{T 2}, C_{T 3}, d^{\prime}} \omega_{T} \log C_{T 2}+\omega_{N} \log C_{N 2}+\beta \omega_{T} \log C_{T 3}, \\
\text { s.t. } \quad & p C_{N 2}+C_{T 2}=y_{2}-d+p y_{N 2}+\frac{d^{\prime}}{1+r}-\rho l \\
& \frac{d^{\prime}}{1+r} \leq \phi\left(y_{2}+p y_{N 2}\right) \\
& C_{T 3}=y_{3}-d^{\prime}
\end{aligned}
$$

The optimality conditions are given by

$$
\begin{aligned}
& \operatorname{FOC}\left(C_{T 2}\right): \lambda=\frac{\omega_{T}}{C_{T 2}} \\
& \operatorname{FOC}\left(d^{\prime}\right): \lambda=\mu+\beta(1+r) \frac{\omega_{T}}{C_{T 3}}
\end{aligned}
$$

where $\lambda$ and $\mu$ are the Lagrangian multipliers associated with equations (32) and (33). 
In the first period, the optimality conditions for $d$ and $l$ are given by

$$
\begin{aligned}
& \frac{\omega_{T}}{C_{T 1}}=\beta(1+r) E_{1}\left[\frac{\omega_{T}}{C_{T 2}}\right] \\
& \frac{\omega_{T}}{C_{T 1}}(1-\theta)=\beta E_{1}\left[\frac{\omega_{T}}{C_{T 2}} \rho\right]
\end{aligned}
$$

Simplifying the last optimality condition, the following relationship holds.

$$
\begin{aligned}
\frac{\omega_{T}}{C_{T 1}}(1-\theta) & =\beta E_{1}\left[\frac{\omega_{T}}{C_{T 2}} \rho\right]=\beta(1+r) E_{1}\left[\frac{\omega_{T}}{C_{T 2}} \frac{p}{E[p]}\right] \\
& =\beta(1+r) \frac{E_{1}\left[\frac{\omega_{T}}{C_{T 2}}\right] E_{1}[p]+\operatorname{cov}\left(\frac{\omega_{T}}{C_{T 2}}, p\right)}{E[p]} \\
& <\beta(1+r) E_{1}\left[\frac{\omega_{T}}{C_{T 2}}\right]
\end{aligned}
$$

We can also define the marginal benefit function for issuing local-currency debt as follows

$$
M B\left(d^{*}, l, \theta\right) \equiv \frac{\omega_{T}}{C_{T 1}}(1-\theta)-\beta E_{1}\left[\frac{\omega_{T}}{C_{T 2}} \rho\right]
$$

We can see that $M B\left(d^{*}, l, 0\right)>0$ and $M B\left(d^{*}, l, 1\right)<0$. Furthermore, $M B_{d^{*}}<0, M B_{l}<0$ and $M B_{\theta}<0$. Therefore, there exists $\underline{\theta}$ such that $M B\left(d^{*}, l, \underline{\theta}\right)=0$. For $\theta<\underline{\theta}, M B\left(d^{*}, l, \theta\right)>$ $M B\left(d^{*}, l, \underline{\theta}\right)=0$. The equilibrium condition features a corner solution with only local currency issuance. Similarly, define $\bar{\theta}$ satisfying $M B\left(d^{*}, 0, \bar{\theta}\right)=0$. In this case, for $\theta>\bar{\theta}$, $M B\left(d^{*}, l, \theta\right)<M B\left(d^{*}, 0, \bar{\theta}\right)=0$ and the equilibrium features zero local-currency debt. In the case of $\theta \in(\underline{\theta}, \bar{\theta})$, there is a combination of local-currency and dollar debt. Furthermore, one can also show that as $\theta$ increases $l$ decreases. Similarly, one can show that an increase in $\theta$ increases $d$. 
The problem of the social planner is given as follows.

$$
\begin{array}{ll}
\max _{d, l, C_{T 1}, C_{T 2}, d^{\prime}, C_{T 3}} & \omega_{T} \log C_{T 1}+\beta E\left[\omega_{T} \log C_{T 2}+\omega_{N} \log y_{N 2}+\beta \omega_{T} \log C_{T 3}\right] \\
\text { s.t. } & C_{T 1}=\frac{d}{1+r}+(1-\theta) l \\
& C_{T 2}=y_{2}-d+\frac{d^{\prime}}{1+r}-\rho\left(C_{T 2}, E\left[C_{T 2}\right]\right) l \\
& \frac{d^{\prime}}{1+r} \leq \phi\left(y_{2}+\frac{\omega_{N}}{\omega_{T}} C_{T 2}\right) \\
& C_{T 3}=y_{3}-d^{\prime}
\end{array}
$$

The optimality conditions are given by

$$
\begin{aligned}
& \operatorname{FOC}(d): \frac{\omega_{T}}{C_{T 1}}=\beta(1+r) E\left[\lambda^{C}\right] \\
& \operatorname{FOC}(l): \frac{\omega_{T}}{C_{T 1}}(1-\theta)=\beta E\left[\lambda^{C} \rho\right] \\
& \operatorname{FOC}\left(C_{T 2}\right): \lambda^{C}=\frac{\frac{\omega_{T}}{C_{T 2}}+\phi \mu^{C} \frac{\omega_{N}}{\omega_{T}}}{1+l\left(\frac{\partial \rho}{\partial C_{T 2}}+f\left(y_{2}\right) \frac{\partial \rho}{\partial E\left[C_{T 2}\right]}\right)} \\
& \operatorname{FOC}\left(d^{\prime}\right): \lambda^{C}=\mu^{C}+\beta(1+r) \frac{\omega_{T}}{C_{T 3}}
\end{aligned}
$$

where $\lambda^{C}, \mu^{C}$ are the Lagrangian multipliers for the period-2 budget constraint and collateral constraint respectively and $f\left(y_{2}\right)$ is the density function of state $y_{2}$ at time 2 .

To implement the social planner's allocation, one need three sets of capital controls $\left\{\tau_{d}, \tau_{l}, \tau d^{\prime}\right\}$ together with lump-sum transfers $\left\{T, T^{\prime}\right\}$. With those capital control policies, the budget constraints for the social planner changes into

$$
\begin{aligned}
& C_{T 1}=\frac{d}{1+r}\left(1-\tau_{d}\right)+l(1-\theta)\left(1-\tau_{l}\right)+T \\
& p C_{N 2}+C_{T 2}=p y_{N 2}+y_{2}-d-\rho l+\frac{d^{\prime}}{1+r}\left(1-\tau_{d^{\prime}}\right)+T^{\prime}
\end{aligned}
$$

with $T=\tau_{d} \frac{d}{1+r}+l(1-\theta) \tau_{l}$ and $T^{\prime}=\frac{d^{\prime}}{1+r} \tau_{d^{\prime}}$. 
By comparing the first order conditions, one need

$$
\begin{aligned}
\tau_{d} & =\beta(1+r) E_{1}\left[\frac{\phi \mu^{C} \frac{\omega_{N}}{\omega_{T}}-\frac{\omega_{T}}{C_{T 2}} l\left(\frac{\partial \rho}{\partial C_{T 2}}+f\left(y_{2}\right) \frac{\partial \rho}{\partial E\left[C_{T 2}\right]}\right)}{1+l\left(\frac{\partial \rho}{\partial C_{T 2}}+f\left(y_{2}\right) \frac{\partial \rho}{\partial E\left[C_{T 2}\right]}\right)}\right] /\left(\frac{\omega_{T}}{C_{T 1}}\right) \\
\tau_{l} & =\beta E_{1}\left[\frac{\phi \mu^{C} \frac{\omega_{N}}{\omega_{T}}-\frac{\omega_{T}}{C_{T 2}} l\left(\frac{\partial \rho}{\partial C_{T 2}}+f\left(y_{2}\right) \frac{\partial \rho}{\partial E\left[C_{T 2}\right]}\right)}{1+l\left(\frac{\partial \rho}{\partial C_{T 2}}+f\left(y_{2}\right) \frac{\partial \rho}{\partial E\left[C_{T 2}\right]}\right)} \rho\right] /\left(\frac{\omega_{T}}{C_{T 1}}\right) /(1-\theta) \\
\tau_{d^{\prime}} & =\frac{l\left(\frac{\partial \rho}{\partial C_{T 2}}+f\left(y_{2}\right) \frac{\partial \rho}{\partial E\left[C_{T 2}\right]}\right)}{1+l\left(\frac{\partial \rho}{\partial C_{T 2}}+f\left(y_{2}\right) \frac{\partial \rho}{\partial E\left[C_{T 2}\right]}\right)}
\end{aligned}
$$

\section{F.8 Proof of Proposition 11}

Proof. Define the net worth at the beginning of period 2 by $m=(1-s) y_{2}-d$. The state variables in period 2 include $\left\{m, s, y_{2}\right\}$. The original problem can be written as

$$
\begin{aligned}
& \max _{s, d} \omega_{T} \log C_{T 1}+\beta E_{1}\left[V\left(m, s, y_{2}\right)\right], \\
& \text { s.t. } C_{T 1}=s(1-\theta) y_{1}+\frac{d}{1+r}, m=(1-s) y_{2}-d .
\end{aligned}
$$

where $V\left(m, s, y_{2}\right)$ is given by

$$
\begin{aligned}
V\left(m, s, y_{2}\right)= & \max _{C_{N 2}, C_{T 2}, C_{T 3}, d^{\prime}, s^{\prime} \in[0,1-s]} \omega_{T} \log C_{T 2}+\omega_{N} \log C_{N 2}+\beta \omega_{T} \log C_{T 3}, \\
\text { s.t. } \quad & p C_{N 2}+C_{T 2}=m+p y_{N 2}+\frac{d^{\prime}}{1+r}+s^{\prime}(1-\theta) \frac{y_{3}}{1+r} \\
& \frac{d^{\prime}}{1+r} \leq \phi\left((1-s) y_{2}+p y_{N 2}\right) \\
& C_{T 3}=y_{3}-d^{\prime}-\left(s+s^{\prime}\right) y_{3}
\end{aligned}
$$

Period 2's problem The optimality conditions in period 2 are given by

$$
\begin{aligned}
& \operatorname{FOC}\left(C_{T 2}\right): \lambda=\frac{\omega_{T}}{C_{T 2}} \\
& \operatorname{FOC}\left(d^{\prime}\right): \lambda=\mu+\beta(1+r) \frac{\omega_{T}}{C_{T 3}} \\
& \operatorname{FOC}\left(s^{\prime}\right): \lambda=\theta \lambda+\beta(1+r) \frac{\omega_{T}}{C_{T 3}}
\end{aligned}
$$


where $\lambda$ and $\mu$ are the Lagrangian multipliers associated with equations (36) and (37), respectively.

Depending on the state variables $\left\{m, s, y_{2}\right\}$, the financial constraint might be either slack or binding. When the constraint is slack, i.e. $\mu=0$, we have $s^{\prime}=0$ since the bond financing is cheaper than the equity financing. In this case, the desired level of bond financing is given by

$$
d^{\prime}=\frac{(1-s) y_{3}-\beta(1+r) m}{1+\beta}
$$

The constraint is slack iff

$$
\frac{d^{\prime}}{1+r} \leq \phi\left(\frac{\omega_{N}}{\omega_{T}} C_{T 2}+(1-s) y_{2}\right)=\phi\left(\frac{\omega_{N}}{\omega_{T}}\left(m+\frac{d^{\prime}}{1+r}\right)+(1-s) y_{2}\right) \leq \frac{\phi \frac{\omega_{N}}{\omega_{T}} m+\phi(1-s) y_{2}}{1-\phi \frac{\omega_{N}}{\omega_{T}}}
$$

When this condition is violated, $\mu>0$, the interior solution of $\left\{C_{T 2}, C_{T 3}, s^{\prime}\right\}$ is given by

$$
\begin{aligned}
& C_{T 2}=m+s^{\prime}(1-\theta) \frac{y_{3}}{1+r}+\phi\left((1-s) y_{2}+\frac{\omega_{N}}{\omega_{T}} C_{T 2}\right) \\
& C_{T 3}=\left(1-s-s^{\prime}\right) y_{3}-(1+r) \phi\left((1-s) y_{2}+\frac{\omega_{N}}{\omega_{T}} C_{T 2}\right), \\
& (1-\theta) \frac{\omega_{T}}{C_{T 2}}=\beta(1+r) \frac{\omega_{T}}{C_{T 3}}
\end{aligned}
$$

The solution $s^{\prime}$ is given by

$$
s^{\prime}=s^{\prime}\left(y_{2}, y_{3}, s, d\right) \equiv \frac{(1-s)\left[y_{3}-\phi(1+r) y_{2}\right]-\frac{(1+r)\left(\beta /(1-\theta)+\phi \omega_{N} / \omega_{T}\right)}{1-\phi \omega_{N} / \omega_{T}}\left[(1-\phi)(1-s) y_{2}-d\right]}{y_{3}+\frac{\left(\beta /(1-\theta) \phi \omega_{N} / \omega_{T}\right)(1-\theta) y_{3}}{1-\phi \omega_{N} / \omega_{T}}}
$$

When $s^{\prime}\left(y_{2}, y_{3}, s, d\right)>1-s$, the allocation is given by the following conditions

$$
\begin{aligned}
& C_{T 2}=m+s^{\prime}(1-\theta) \frac{y_{3}}{1+r}+\phi\left((1-s) y_{2}+\frac{\omega_{N}}{\omega_{T}} C_{T 2}\right) \\
& C_{T 3}=y_{3}\left(1-s-s^{\prime}\right) y_{3}-(1+r) \phi\left((1-s) y_{2}+\frac{\omega_{N}}{\omega_{T}} C_{T 2}\right), \\
& s^{\prime}=1-s
\end{aligned}
$$

Period 1's problem The allocation in the first period is given by the following optimality 
conditions

$$
\begin{aligned}
& \operatorname{FOC}(d): \frac{\omega_{T}}{C_{T 1}}=\beta(1+r) \beta E_{1}\left[\frac{\partial V}{\partial m}\right] \\
& \operatorname{FOC}(s): \frac{\omega_{T}}{C_{T 1}}(1-\theta) y_{1}=\beta(1+r) \beta E_{1}\left[\frac{\partial V}{\partial m} y_{2}-\frac{\partial V}{\partial s}\right]
\end{aligned}
$$

Social planner's problem The social planner internalizes the general equilibrium effect through the real exchange rate. Her problem is given by

$$
\begin{aligned}
& \max _{s, d} \omega_{T} \log C_{T 1}+\beta E_{1}\left[V^{S P}\left(m, s, y_{2}\right)\right], \\
& \text { s.t. } C_{T 1}=s(1-\theta) y_{1}+\frac{d}{1+r}, m=(1-s) y_{2}-d .
\end{aligned}
$$

where $V^{S P}\left(m, s, y_{2}\right)$ is given by

$$
\begin{aligned}
V^{S P}\left(m, s, y_{2}\right)= & \max _{C_{T 2}, C_{T 3}, d^{\prime}, s^{\prime} \in[0,1-s]} \omega_{T} \log C_{T 2}+\omega_{N} \log y_{N 2}+\beta \omega_{T} \log C_{T 3}, \\
\text { s.t. } & C_{T 2}=m+\frac{d^{\prime}}{1+r}+s^{\prime}(1-\theta) \frac{y_{3}}{1+r} \\
& \frac{d^{\prime}}{1+r} \leq \phi\left((1-s) y_{2}+\frac{\omega_{N}}{\omega_{T}} C_{T 2}\right) \\
& C_{T 3}=y_{3}-d^{\prime}-\left(s+s^{\prime}\right) y_{3}
\end{aligned}
$$

The optimality conditions in the second period are given by

$$
\begin{aligned}
& \operatorname{FOC}\left(C_{T 2}\right): \lambda^{S P}=\frac{\omega_{T}}{C_{T 2}}+\phi \frac{\omega_{N}}{\omega_{T}} \mu^{S P} \\
& \operatorname{FOC}\left(d^{\prime}\right): \lambda^{S P}=\mu^{S P}+\beta(1+r) \frac{\omega_{T}}{C_{T 3}} \\
& \operatorname{FOC}\left(s^{\prime}\right): \lambda^{S P}=\theta \lambda^{S P}+\beta(1+r) \frac{\omega_{T}}{C_{T 3}}
\end{aligned}
$$

where $\lambda^{S P}$ and $\mu^{S P}$ are the Lagrangian multipliers associated with equations (39) and (40), respectively. The allocation when the constraint is slack is the same as in the competitive 
equilibrium. However, the allocation when the constraint binds is different and given by

$$
\begin{aligned}
& C_{T 2}=m+s^{\prime}(1-\theta) \frac{y_{3}}{1+r}+\phi\left((1-s) y_{2}+\frac{\omega_{N}}{\omega_{T}} C_{T 2}\right) \\
& C_{T 3}=y_{3}\left(1-s-s^{\prime}\right) y_{3}-d^{\prime}, \\
& \left(1-\theta \frac{1-\phi \omega_{N} / \omega_{T}}{1-\theta \phi \omega_{N} / \omega_{T}}\right) \frac{\omega_{T}}{C_{T 2}}=\beta(1+r) \frac{\omega_{T}}{C_{T 3}}
\end{aligned}
$$

Therefore, one needs to put an ex-post tax on equity issuance. Suppose we introduce a tax $\tau_{s}^{\prime}$ on equity issuance and a lump-sum transfer as follows.

$$
p C_{N 2}+C_{T 2}=m+p y_{N 2}+\frac{d^{\prime}}{1+r}+\left(1-\tau_{s}^{\prime}\right) s^{\prime}(1-\theta) \frac{y_{3}}{1+r}+T
$$

where $T=\tau_{s}^{\prime} s^{\prime}(1-\theta) \frac{y_{3}}{1+r}$.

In this case, the optimality condition for $s^{\prime}$ becomes

$$
(1-\theta)\left(1-\tau_{s}^{\prime}\right) \frac{\omega_{T}}{C_{T 2}}=\beta(1+r) \frac{\omega_{T}}{C_{T 3}}
$$

We need $\tau_{s}^{\prime}=-\frac{\theta \phi \omega_{N} / \omega_{T}}{1-\theta \phi \omega_{N} / \omega_{T}}<0$ to close the gap between the social planner's and the private agents' allocations. Given that the wedge is negative, the private agents' choice features too little equity financing relative to relative to that of the social planner.

The inefficiency also shows up in the different valuations of wealth $\lambda^{S P}$ and $\lambda$. For the social planner, the envelope theorem implies that

$$
\frac{\partial V^{S P}}{\partial m}=\lambda^{S P}=\frac{\omega_{T}}{C_{T 2}}+\phi \frac{\omega_{N}}{\omega_{T}} \mu^{S P} \geq \frac{\omega_{T}}{C_{T 2}}=\frac{\partial V}{\partial m}
$$

Therefore, capital controls in the first period are needed to correct this inefficiency. Furthermore, there will be overborrowing due to the positive wedge above. The proof is similar to that in Appendix F.5. To fully correct the externality, the social planner has to use both an ex-ante tax on capital flows in the first period and an ex-post policy intervention $\tau_{s}^{\prime}$. 